\title{
Consumer Preferences for Alternative Fuel Vehicles: A Discrete Choice Analysis
}

\author{
André Hackbarth* and Reinhard Madlener \\ Institute for Future Energy Consumer Needs and Behavior (FCN), School of Business and \\ Economics / E.ON Energy Research Center, RWTH Aachen University, Mathieustrasse 10, \\ 52074 Aachen, Germany
}

December 2011, revised December 2012

\begin{abstract}
In this paper we analyze the potential demand for privately used alternative fuel vehicles (AFVs), based on a nationwide survey in Germany among (potential) car buyers. For this purpose, we applied a stated preference discrete choice experiment, using a wide range of vehicle alternatives (gasoline/diesel, natural gas, hybrid, plugin hybrid, electric, hydrogen) and vehicle attributes. By applying both a multinomial logit model and a mixed (error components) logit model, we estimate the attributes' influence on vehicle choice and calculate consumers' willingness-to-pay for the improvement of these attributes. Furthermore, in a scenario analysis, we simulate the impact of monetary and non-monetary policy measures on vehicle choice probabilities. We find that the most promising target group for the adoption of all kinds of AFVs is that of younger, well-educated, and environmentally aware car buyers, who, in the case of electric vehicles, also have the possibility to plug-in their car at home, and who have a high share of city trips and thus need a small car. Moreover, we find that, depending on the vehicle alternative, environmental awareness, and budget constraints for the next vehicle purchase, households are willing to pay substantial amounts for the improvement of fuel cost, driving range, charging infrastructure, $\mathrm{CO}_{2}$ emissions, vehicle tax exemptions, and free parking or bus lane access. Furthermore, the scenario results suggest that conventional vehicles will maintain their dominance in the market, whereas electric and hydrogen vehicles will remain unpopular. The market share of the latter is only expected to rise markedly if massive and multiple policy interventions are implemented. Finally, we find evidence that an increase in the fully electric vehicle's driving range to a level comparable with all other vehicle alternatives has the same impact on its choice probability as would a market-based, multiple measures policy intervention package.
\end{abstract}

Keywords: Discrete choice model, Alternative fuel vehicles, Willingness-to-pay, Stated preferences, Mixed logit, Error components model

JEL Classification Nos.: C25, D12, M38, Q58, R41

\footnotetext{
* Corresponding author. Tel: +49 24180 49834, Fax: +49 24180 49829, E-mail: ahackbarth@eonerc.rwth-aachen.de.
} 


\section{Introduction}

Due to its almost exclusive dependence on fossil fuels, the transportation sector accounts for $32 \%$ of the final energy demand in the European Union, and is responsible for about one fifth of the total European Union greenhouse gas (GHG) emissions (EC, 2011a). Consequently, it is one of the focal points of the European sustainability strategies, which aim at the mitigation of substantial amounts of GHG emissions in several sectors of the economy. For instance, the European Commission has set the ambitious goal of a 60\% reduction of GHG emissions in the transportation sector by 2050 compared to 1990 levels (EC, 2011b). However, the achievement of this objective requires considerable efforts, amongst others the enhancement of the vehicles' fuel efficiency and the substitution of alternative fuels or electricity for gasoline and diesel. Moreover, today's transport system, which is largely based on individual means of transportation, such as passenger cars, has to be changed fundamentally towards a broad utilization of public modes of transport or shared vehicles.

Acknowledging the fact that mobility patterns are difficult to change rapidly, the European Commission adopted several regulations to improve vehicles' specific GHG emissions in the short term. For instance, emission performance standards for new passenger cars were set to $95 \mathrm{gCO}_{2} / \mathrm{km}$ on average by 2020 (EC, 2009b), with gradually stiffened interim targets. Additionally, the European Commission determined that the share of renewable energy should at least amount to $10 \%$ of the final energy consumption in transport by 2020 (EC, 2009a). Beyond that, most European governments have decided to implement furtherreaching programs and regulations to accelerate the diffusion of alternative fuel vehicles (AFVs) in general and electric cars in particular ${ }^{1}$. For example, purchase and tax incentives for (partially) electric or other 'environmentally-friendly' vehicles are granted in Spain, France, the UK, Ireland, Sweden, Belgium, and the Netherlands, to name but a few. These inducements to buy amount up to $€ 9,510$, as in Belgium, or even up to $70 \%$ of the investment, as in Andalucia (for a useful review of electric vehicle promotion strategies, see e.g. ACEA, 2012).

\footnotetext{
${ }^{1}$ AFVs comprise vehicles that run on liquid or gaseous fuels other than gasoline and diesel, or at least partly on electricity, e.g. biofuels, natural gas (liquefied petroleum gas (LPG) or compressed natural gas (CNG)), hydrogen (e.g. fuel cell vehicles), (plug-in) hybrid electric, and fully electric vehicles.
} 
In Germany, the largest European economy, with its pronounced automotive manufacturing sector, the government has set the goal to get one million electric vehicles on the road by 2020 and to become a leading market for and provider of electric mobility (Bundesregierung, 2009). To reach these targets, research on various technical, economic, and behavioral aspects is coordinated centrally and will be funded by more than $€ 1.5$ billion in total up to 2013 (Bundesregierung, 2011). In addition, a ten-year motor vehicle tax exemption for electric vehicles was introduced in a first step. Further monetary incentives, such as advantageous taxation rules for commercially used electric vehicles, have been initiated, and several non-monetary buying inducements are under consideration, such as the permission for bus lane usage or special parking areas (BMF, 2011; Bundesregierung, 2011). However, in contrast to the European countries mentioned before, and to the loudly voiced annoyance of German vehicle manufacturers, purchase premiums for vehicles with electrified drivetrains are not granted.

Even though electric mobility is currently the primary topic of interest of German policymakers, other alternative fuels are being supported as well. For example, tax reductions for natural gas fuels have been recently prolonged until 2018. Moreover, a minimum quota of 6.25\% for biofuels to replace gasoline and diesel has been introduced (BImSchG, 2011), and a public-private partnership, which runs until 2016 and provides $€ 1.4$ billion of funding, has been established to boost research on hydrogen and fuel cells (BMVBS/BMWi/BMBF, 2006).

Despite these diversified endeavors of the government and administration, the assortment of AFVs is still limited. Thus, it is hardly surprising that AFVs have not penetrated the market yet to a large extent and amount to only about $1 \%$ of the overall vehicle stock in Germany (KBA, 2011). However, the diffusion of AFVs might rise sharply in the next couple of years for at least two reasons. First, all major vehicle manufacturers have started to bring massproduced, and thus affordable, plug-in hybrid or pure electric vehicles to market and have announced that they will do so in the next couple of years with hydrogen-fueled vehicles. Second, consumer prices for gasoline and diesel in 2012 (Q1-Q3) were at an all-time high and expected to increase further (ADAC, 2012), which makes non-conventional fuels even more attractive. For a fast market penetration of AFVs, however, it is necessary that also the remaining features of AFVs match consumer preferences sufficiently.

The purpose of this paper is to assess the relative impact of the most important vehicle attributes, such as purchase price, fuel cost, driving range, fuel availability, $\mathrm{CO}_{2}$ emissions, 
refueling time, and governmental incentives, on the potential demand for AFVs. Additionally, we tackle the question of how much vehicle buyers are willing to pay for an improvement of principal vehicle characteristics, such as a reduction of the purchase price, an extension of the driving range or the acceleration of the battery recharging process for electric vehicles. On this basis, we simulate how such beneficial changes affect the potential market shares of the different propulsion technologies in a scenario-based analysis, whereby we predominantly focus on the effects that assorted governmental incentive schemes wield on vehicle choice. Moreover, we examine the acceptance of alternative fuels compared to gasoline and diesel for distinct consumer groups, distinguished by socio-demographic characteristics. Taken together, this information could be particularly helpful for policy-makers and industrial decisionmakers aiming to increase the adoption rate of AFVs in the future by focusing on the improvement or subsidization of the most influential vehicle features and by specifically adjusting their incentive schemes, marketing campaigns, and products to the preference differences between consumer segments.

Our analysis is based on a thorough, Germany-wide, web-based stated preferences discrete choice experiment, carried out among 711 potential car buyers in July and August of 2011. Our study builds on the rich body of literature on the demand for AFVs, which has been primarily carried out in the US (Beggs et al., 1981; Calfee, 1985; Bunch et al., 1993; Golob et al., 1993; Brownstone and Train, 1999; Brownstone et al., 2000; Axsen et al., 2009; Hidrue et al., 2011; Musti and Kockelman, 2011) and Canada (Ewing and Sarigöllü, 2000; Horne et al., 2005; Potoglou and Kanaroglou, 2007; Mau et al., 2008; Axsen et al., 2009), but also in Europe (Dagsvik et al., 2002; Batley et al., 2004; Caulfield et al., 2010; Mabit and Fosgerau, 2011; Lebeau et al., 2012; Achtnicht, 2012; Achtnicht et al., 2012; Ziegler, 2012), South Korea (Ahn et al., 2008), and Japan (Ito et al., 2013). The works of Achtnicht (2012), Ziegler (2012), and Achtnicht et al. (2012), which are all based on the same data set, have to be pointed out, as they are, to the best of our knowledge, the only ones considering the German market, and, hence, more closely related to our research. Achtnicht (2012) analyzed the relevance of $\mathrm{CO}_{2}$ emissions in vehicle choice decisions and, by applying a mixed (random parameters) logit model, found that, subject to gender, age, and education, potential car buyers are willing to pay substantial amounts for the abatement of vehicle emissions. Achtnicht et al. (2012) examined the influence of fuel availability on vehicle choice. Based on a standard logit model they found that the density of the respective refueling infrastructure 
positively influences the demand for AFVs and, hence, is a prerequisite for significant vehicle adoption. They also show a significant impact of several socio-demographic characteristics, such as age and environmental awareness, on the potential market shares of AFVs. Their results further reveal that German car buyers are ceteris paribus more reluctant towards some types of propulsion technology, namely biofuel and electricity, than towards conventional ones. In his comprehensive study, Ziegler (2012) deepens the understanding of the influence that individual characteristics exercise on vehicle choice. Implementing flexible multinomial probit models, numerous socio-demographic variables are found to positively affect the demand for otherwise disfavored AFVs, such as biofuel, hydrogen, and electric cars. For example, the results suggest that younger respondents prefer natural gas, biofuel, hydrogen, and electric vehicles, that males choose natural gas and hydrogen vehicles more often, and that environmental awareness increases the stated preference for biofuel, hydrogen, and electrically-driven vehicles.

Similarly to this literature, our analysis is based on a broad variety of drivetrain technologies and vehicle characteristics, i.e. we also consider conventional, natural gas, hybrid, biofuel, electric, and hydrogen vehicles vis-a-vis purchase price, fuel cost, $\mathrm{CO}_{2}$ emissions, and service station availability. However, we essentially expand the limitations of these studies in two ways. First, we introduce plug-in hybrid electric vehicles (PHEVs) and their particularities - two different refueling options with varying refueling times - as choice alternatives in a discrete choice experiment. ${ }^{2}$ Second, we characterize some of the vehicle alternatives with additional attributes, i.e. the driving range on a full tank and/or battery, the refueling and/or recharging time, and potential governmental actions to incentivize the respective vehicle choice, an approach which has not been taken for Germany before. From our point of view, the inclusion of the driving range and the recharging time is essential in order to more realistically analyze consumer preferences regarding electric mobility. We are therefore able to contribute to the current research and debate about the best strategy for a fostering of electric vehicles by estimating willingness-to-pay (WTP) measures for driving

\footnotetext{
${ }^{2}$ To be precise, PHEVs have already been introduced in a choice experiment by Musti and Kockelman (2011). However, in their survey, the different vehicle alternatives were only described by purchase price and fuel cost at fixed values and, thus, not varied by design.
} 
range, battery fast-charging, and governmental monetary and non-monetary incentives, and by analyzing the effect of their improvement in a scenario-based simulation.

On that account, we methodologically follow the approach of Brownstone and Train (1999) and apply a mixed error components logit (MXL) model in addition to a standard multinomial logit (MNL) model. The MXL model allows for both correlation between the different vehicle alternatives and taste persistency in repeated choices of a single respondent in a parsimonious way and, hence, leads to better results regarding model fit than does the MNL model.

The remainder of this paper is organized as follows: In section 2, we outline the survey conducted and the data gathered. The methodological approach is introduced in section 3 . In section 4, the empirical results of the discrete choice models are reported and discussed, the respondents' WTP for an improvement of the considered vehicle features calculated, and the simulation results of different potential policy scenarios outlined. In section 5, we summarize and conclude.

\section{Survey Design and Data}

The data for our empirical analysis of the potential demand for AFVs in Germany were collected in a nationwide, web-based survey conducted in July and August 2011. The sample was drawn from a commercial online panel, with the restriction that the last vehicle purchase of potential respondents did not date back more than one year, or that the potential respondents intended to purchase a new car within the next year. In total, 711 respondents completed the survey. Although the sample was supposed to display the German population regarding socio-economic and socio-demographic factors, as well as geographical allocation, a comparison with the German population statistics shows noteworthy differences. As can be seen in Table 1, our survey under-represents individuals with low income, while it overrepresents younger and more highly educated people, which, however, is a common finding in web-based surveys. Moreover, single-person households and households without a car are under-represented in our sample. In contrast, our sample almost perfectly reflects the regional distribution of the population among the 16 German federal states (not shown in the Table). 
Table 1: Demographic characteristics of the sample and the German population

\begin{tabular}{|c|c|c|c|}
\hline Variable & Value & Sample (\%) & German population (\%) \\
\hline \multirow[t]{2}{*}{ Gender } & Female & 50.4 & 50.9 \\
\hline & Male & 49.6 & 49.1 \\
\hline \multirow[t]{4}{*}{ Age } & 18 to 24 & 8.4 & 9.8 \\
\hline & 25 to 44 & 49.4 & 31.3 \\
\hline & 45 to 64 & 38.0 & 34.3 \\
\hline & 65 or above & 4.2 & 24.6 \\
\hline \multirow{4}{*}{$\begin{array}{l}\text { Household income per } \\
\text { month }\end{array}$} & Less than $€ 2,000$ & 17.9 & 49.5 \\
\hline & $€ 2,000$ to $€ 5,999$ & 60.4 & 40.3 \\
\hline & $€ 6,000$ or more & 2.7 & 2.7 \\
\hline & Not stated & 19.0 & 7.5 \\
\hline \multirow[t]{5}{*}{ Education } & No form of school leaving qualification & 0.1 & 7.7 \\
\hline & Secondary general school leaving & 6.6 & 37.3 \\
\hline & qualification & 29.8 & 29.0 \\
\hline & Intermediate school leaving qualification & 63.5 & 26.0 \\
\hline & $\begin{array}{l}\text { Higher education entrance qualification or } \\
\text { university (of applied sciences) degree }\end{array}$ & & \\
\hline \multirow[t]{8}{*}{ Vehicle segment } & Mini / small cars & $23.3 \%$ & $26.2 \%$ \\
\hline & Medium cars & $27.6 \%$ & $27.5 \%$ \\
\hline & Large cars & $21.0 \%$ & $18.9 \%$ \\
\hline & Executive cars & $6.5 \%$ & $5.6 \%$ \\
\hline & Luxury cars & $1.5 \%$ & $0.6 \%$ \\
\hline & Multi-purpose cars & $11.0 \%$ & $8.5 \%$ \\
\hline & SUVs & $4.4 \%$ & $4.2 \%$ \\
\hline & Sport coupés and others & $4.7 \%$ & $8.1 \%$ \\
\hline \multirow{5}{*}{$\begin{array}{l}\text { Number of household } \\
\text { vehicles }\end{array}$} & 0 & 5.2 & 17.7 \\
\hline & 1 & 52.5 & 53.0 \\
\hline & 2 & 35.6 & 24.2 \\
\hline & 3 & 5.6 & 4.0 \\
\hline & 4 or more & 1.1 & 1.0 \\
\hline \multirow{5}{*}{$\begin{array}{l}\text { Number of persons in } \\
\text { household }\end{array}$} & 1 & 15.3 & 40.2 \\
\hline & 2 & 39.8 & 34.2 \\
\hline & 3 & 23.5 & 12.6 \\
\hline & 4 & 15.6 & 9.5 \\
\hline & 5 or more & 5.8 & 3.4 \\
\hline
\end{tabular}

Source: Own calculations, Destatis (2011), SOEP (2011), MiD (2010), KBA (2012)

The survey consisted of five main sections. In the first section, respondents had to provide detailed information about existing and planned car ownership, driving habits, and influencing factors during the car purchase decision, such as vehicle fuel type and vehicle segment, daily and annual mileage, and the allocation of the latter on highway and city trips. The second section comprised a question about respondents' familiarity with AFVs, a detailed introduction to alternative propulsion technologies, and, as the center piece of the survey, the stated preferences discrete choice experiment, which will be described in detail below. In the third section, respondents were asked about the importance of a wide range of vehicle attributes (including those used in the choice experiment) in their purchase decision. In the 
fourth section, respondents had to indicate their level of agreement with a variety of statements regarding environmental concern, environmentally-friendly behavior, and the general interest they have in cars. For instance, a respondent's environmental awareness was measured with the additive scale developed by Preissendörfer (1999), which consists of 9 statements that have to be rated on a 5-level Likert scale according to the degree of agreement. We opted for this scale, as it is also used, each time in a slightly modified version, in the biannual representative survey of environmental consciousness of the German population conducted by the Federal Environment Agency. Finally, the fifth section included several socio-economic and socio-demographic questions, such as age, income, and educational level, but also questions regarding specifics of the respondents' place of residence (e.g. whether they have the possibility to plug in an electric vehicle at their customary parking lot), and such concerning their public transport utilization habits.

As already mentioned, a stated preferences discrete choice experiment was at the center of our survey. Respondents were asked to choose the vehicle they preferred most from a set of hypothetical passenger cars. The experiment consisted of seven different fuel types, which also served as labels for the vehicles: conventional (gasoline, diesel), natural gas (CNG, LPG), hybrid, PHEV, electric, biofuel, and hydrogen. The wide range of fuels was chosen to cover all propulsion technologies that are already available on the German market, or at least will be in the near future, such as hydrogen (fuel cell electric vehicles). The seven types of vehicles considered were additionally described by up to eight attributes: (1) purchase price, (2) fuel cost, (3) $\mathrm{CO}_{2}$ emissions, (4) driving range, (5) fuel availability, (6) refueling time, (7) battery recharging time, and (8) policy incentives. We selected these attributes because they do not only correspond to the most common vehicle characteristics applied in the aforementioned earlier studies, but also to the most important vehicle features affecting the car purchasing process in Germany ${ }^{3}$. Table 2 shows in detail the attributes used and their levels by fuel type. Respondents had the possibility to get in-depth information about the different vehicle alternatives, attributes and attribute levels applied in our experiment by clicking on a particular vehicle characteristic during the survey. 
To reduce the hypothetical bias in our choice experiment, respondents were solicited to treat the choice decisions as if it were a real purchase decision. Furthermore, in the task description, respondents were explicitly instructed to treat the vehicles as being absolutely identical regarding any other attributes but the ones utilized in the experiment.

Table 2: Attributes and levels of the discrete choice experiment

\begin{tabular}{|c|c|c|c|}
\hline Variable & Alternative (Fuel type) & $\begin{array}{c}\text { Number of } \\
\text { levels }\end{array}$ & Levels \\
\hline Purchase price & $\begin{array}{l}\text { Conventional, LPG/CNG, Hybrid, PHEV, } \\
\text { Electric, Biofuel, Hydrogen }\end{array}$ & 3 & $\begin{array}{l}75 \%, 100 \%, 125 \% \text { of stated } \\
\text { reference value (in } € \text { ) }\end{array}$ \\
\hline $\begin{array}{l}\text { Fuel cost per } \\
100 \mathrm{~km}\end{array}$ & $\begin{array}{l}\text { Conventional, LPG/CNG, Hybrid, PHEV, } \\
\text { Electric, Biofuel, Hydrogen }\end{array}$ & 3 & $€ 5, € 15, € 25$ \\
\hline \multirow[t]{2}{*}{$\mathrm{CO}_{2}$ emissions } & Conventional, LPG/CNG, Hybrid & 3 & $\begin{array}{l}50 \%, 75 \%, 100 \% \text { of average } \\
\text { current vehicle }\end{array}$ \\
\hline & PHEV, Electric, Biofuel, Hydrogen & 3 & $\begin{array}{l}0 \%, 50 \%, 100 \% \text { of average } \\
\text { current vehicle }\end{array}$ \\
\hline \multirow[t]{2}{*}{ Driving range } & $\begin{array}{c}\text { Conventional, LPG/CNG, Hybrid, PHEV, } \\
\text { Biofuel, Hydrogen }\end{array}$ & 3 & $400 \mathrm{~km}, 700 \mathrm{~km}, 1,000 \mathrm{~km}$ \\
\hline & Electric & 3 & $100 \mathrm{~km}, 400 \mathrm{~km}, 700 \mathrm{~km}$ \\
\hline \multirow[t]{2}{*}{ Fuel availability } & Conventional, Hybrid & 2 & $60 \%, 100 \%$ of all stations \\
\hline & $\begin{array}{c}\text { LPG/CNG, PHEV, Electric, Biofuel, } \\
\text { Hydrogen }\end{array}$ & 3 & $20 \%, 60 \%, 100 \%$ of all stations \\
\hline Refueling time & $\begin{array}{c}\text { Conventional, LPG/CNG, Hybrid, PHEV, } \\
\text { Biofuel, Hydrogen }\end{array}$ & 2 & $5 \mathrm{~min}, 10 \mathrm{~min}$ \\
\hline $\begin{array}{l}\text { Battery } \\
\text { recharging time }\end{array}$ & PHEV, Electric & 3 & $10 \mathrm{~min}, 1 \mathrm{~h}, 6 \mathrm{~h}$ \\
\hline Policy incentives & PHEV, Electric, Biofuel, Hydrogen & 3 & $\begin{array}{l}\text { None, No vehicle tax, Free } \\
\text { parking and bus lane access }\end{array}$ \\
\hline
\end{tabular}

To further increase realism in the hypothetical vehicle choices, the purchase price was customized for each respondent based on statements about the (expected) price range of their latest or next car, respectively. Specifically, it was allowed to vary from this value by $\pm 25 \%$ for all types of vehicle alternatives. ${ }^{4}$ Such a tailoring of attribute levels in experiments is a

${ }^{3}$ According to a representative survey among German car users, the vehicle features that have a (very) important influence on vehicle purchase are, in descending order of importance: fuel consumption, purchase price, $\mathrm{CO}_{2}$ emissions, motor vehicle tax level, size, fuel type, design, make, and engine power (Dena, 2010).

\footnotetext{
${ }^{4}$ Note that such a price range is unrealistic for some AFVs, especially electric vehicles (which today exceed the purchase prices of comparable conventional vehicles by more than 25\%). However, it was chosen to circumvent
} 
common approach in the vehicle choice literature and is primarily applied to monetary attributes (e.g. purchase price, operating cost), fuel consumption or descriptions of vehicle performance.

Fuel cost was displayed in Euro per $100 \mathrm{~km}$ to avoid the unit conversion of other fuel consumption measures (e.g. Euro per liter, $\mathrm{kWh}$ or $\mathrm{kg}$ ), thus making it easily comparable between the different vehicle alternatives, whether propelled by liquid or gaseous fuels or electricity. Identical attribute levels were used for all seven different vehicle alternatives studied.

$\mathrm{CO}_{2}$ emissions were described as being in proportion to the average vehicle of the respondents' favorite car segment, in order to establish more realistic choice situations as if they were characterized by a fixed, segment-invariant measure (e.g. gram of $\mathrm{CO}_{2}$ per kilometer). Additionally, $\mathrm{CO}_{2}$ emissions were allowed to vary by vehicle alternative. Thus, in contrast to conventional and natural gas vehicles, the $\mathrm{CO}_{2}$ emissions of the non-fossil fuel vehicles were additionally allowed to be zero. Although to some extent unrealistic (since fuel production leads to emissions in almost all cases), we incorporated this emission value in our survey, because AFVs, especially electric vehicles, are often promoted as being very environmentally friendly and emission-free. Besides, hydrogen fuel cell and electric vehicles theoretically have the potential to drive almost emission-free, provided that electricity and hydrogen are generated with renewable energies.

The driving range was defined as the distance that could be traveled on a full tank and/or battery. As the cruising radius of electric vehicles is limited compared to other propulsion technologies, the levels of the driving range attribute were restricted for the electric vehicle in the experiment in order to increase realism, even though it has to be recognized that a driving range of $700 \mathrm{~km}$ (the highest attribute level for electric vehicles in the experiment) is still a long way off from today’s perspective.

Fuel availability was modeled with alternative-specific values as well, since a very low density of service stations selling conventional fuels (20\% of all stations) is very unrealistic in the near future. Furthermore, the fuel availability levels used in the experiment are even more parameter estimates more reliable. 
unrealistic for most of the AFVs from today's perspective ${ }^{5}$. However, refueling station densities below $20 \%$ would have frequently led to a rejection of the respective alternatives.

As the length of the battery-charging process is a crucial factor for a substantial market penetration of electric vehicles, we incorporated the recharging time in our experiment. The attribute levels have a great bandwidth to cover current charging options (standard power outlet, 6 hours to fully charge the battery) but also prospective infrastructural means, such as fast-charging (1 hour) or battery-switching stations (10 minutes).

Since the massive market diffusion of alternative fuels might lead to a prolongation of the refueling process - e.g. due to a decreasing number of fuel pumps that are available per particular fuel type at existing service stations when the number of fuel types increases - we also took the refueling time into account. However, the main reason for doing so was to constantly remind respondents of the unfamiliar particularities of PHEVs. These particularities include two different energy sources with probably dissimilar refueling times and, thus, the possibility to nevertheless travel long distances with only short refueling stops by use of the internal combustion engine, even though battery charging is time-consuming.

As already mentioned, several reasons exist for the utilization of governmental policy incentives as a vehicle attribute in the experiment. First, the German government is considering the introduction of non-monetary incentives (permission for bus lane usage, special parking areas) for (some) AFVs to accelerate their adoption (Bundesregierung, 2011). Second, it has already introduced a monetary incentive - motor vehicle tax exemptions for electric vehicles (BMF, 2011). Third, according to Dena (2010), the motor vehicle tax is one of the most important attributes that German car buyers take into account in their car purchase decisions. Finally, the results concerning the influence of non-monetary incentives on alternative fuel vehicle choice are mixed in the transportation literature: while free parking and permission to drive on high occupancy vehicle lanes with one passenger in the vehicle are statistically not significant in the study of Potoglou and Kanaroglou (2007), express lane

\footnotetext{
${ }^{5}$ For example, an online search revealed that, in 2012, 14,732 gasoline filling stations existed in Germany. At almost 7,500 filling stations natural gas was sold (LPG: 6,577, CNG: 911), while only 2,073 recharging options were publicly accessible for electric vehicles, and bioethanol was available at 337 filling stations. The number of hydrogen filling stations had a low double digit figure (about 35).
} 
access in the study of Horne et al. (2005) is. Thus, an evaluation of the effectiveness of such policy measures in the case of Germany is necessary.

The wide range of seven vehicle alternatives and up to eight attributes leads to a large number of potential vehicle combinations and choice tasks, which is impossible for a respondent to handle. On this account, an alternative-specific, completely randomized fractional factorial design was generated. Each respondent was confronted with 15 separate choice sets, which in our pretest proved to be a manageable amount without leading to noteworthy fatigue or rejection. To reduce task complexity, each seperate choice set consisted of only four out of the seven different vehicle alternatives.

The sample size of 711 respondents, facing 15 choice sets each, led to 10,665 observations. These were used to estimate an MNL and an MXL model, both of which will be introduced in detail in the following.

\section{Methodological Approach and Model Specification}

Our empirical analysis of the stated preference vehicle choice data is mainly based on an MXL model, which, as in our case, extends the MNL model by the inclusion of error components. As a consequence, the MXL model is able to account for unobserved correlation between choice alternatives and, thus, relaxes the restrictive IIA (independence of irrelevant alternatives) assumption of the MNL model ${ }^{6}$. Additionally, it is capable of capturing the panel nature of stated preference discrete choice experiments, which are usually characterized by repeated choices of respondents. In our study, for example, each of the 711 potential car buyers has to complete 15 consecutive choice tasks.

Assuming utility-maximizing behavior, in every choice set the respondents select the alternative that renders the highest level of utility. Unfortunately, utility is unobservable by the researcher, so it has to be modeled as a random variable. Thus, drawing directly from Brownstone and Train (1999) and Train (2003), the utility $U_{n j}$ that decision-maker $n$ receives

\footnotetext{
${ }^{6}$ The IIA assumption states that the ratio of choice probabilities of two alternatives does not depend on the availability or the configuration of the attributes of any other alternative. In other words, the IIA property expresses that a change in the attributes of one alternative proportionately draws from all other alternatives (Train, 2003). In the light of heterogeneous or very dissimilar alternatives, this property can lead to unrealistic substitution patterns.
} 
from alternative $j$ from a finite set of $J$ alternatives (e.g. passenger cars, as in our case) is assumed to be given by

$$
U_{n j}=V_{n j}+\eta_{n j}+\varepsilon_{n j},
$$

where $V_{n j}$ is the deterministic or observable part of utility, and $\eta_{n j}$ together with $\varepsilon_{n j}$ represents the stochastic or unobservable portion of utility. Usually $V_{n j}$ and $\eta_{n j}$ are defined as being linear in parameters, so that $V_{n j}=\beta^{\prime} x_{n j} ; \eta_{n j}$ is denoted as $\eta_{n j}=\mu_{n}^{\prime} z_{n j}$, leading to

$$
U_{n j}=\beta^{\prime} X_{n j}+\mu_{n}^{\prime} Z_{n j}+\varepsilon_{n j},
$$

where $x_{n j}$ is a vector of observed attributes of the vehicle alternative $j$ and socio-demographic characteristics of the respondent $n, z_{n j}$ is a vector of observable variables relating to alternative $j, \beta^{\prime}$ is a vector of unknown fixed parameters, $\mu_{n}^{\prime}$ is a random vector with zero mean, and $\varepsilon_{n j}$ is a random term that is independent and identically distributed according to the type I extreme value or Gumbel distribution. The correlation between alternatives in unobserved attributes is induced by the random terms in $\mu_{n}^{\prime} z_{n j}$, which can be interpreted as error components. The IIA property of the standard MNL model and its restrictive substitution patterns arise from defining all terms in $z_{n j}$ as being identically zero, such that no correlation in the unobserved portion of utility exists over alternatives. With non-zero error components, however, utility is correlated over alternatives, with the complexity of the correlation structure depending on the specification of $Z_{n j}$.

In our model specification, we decided in favor of a correlation structure comparable to the nested logit model - i.e. the different vehicle alternatives are grouped into mutually exclusive nests - because, following on extensive tests with numerous nested and cross-nested specifications of the error components, this fits our data best regarding log likelihood. In such an equivalent to the nested logit model, the error components are specified as follows: for each distinct nest $k$, a dummy variable $d_{j k}$ is created, so that $d_{j k}=1$ for each alternative $j$ in the nest and $d_{j k}=0$ otherwise. With $K$ non-overlapping nests and $z_{n j}$ defined as a vector composed of these dummy variables, the error components are $\mu_{n}^{\prime} z_{n j}=\sum_{k=1}^{K} \mu_{n k} d_{j k}$. As a consequence, $\mu_{n k}$ enters the utility of each alternative in nest $k$, inducing correlation among these alternatives. Since it does not enter the utility functions of any of the alternatives in 
other nests, alternatives in different nests are uncorrelated. The random term $\mu_{n k}$ is specified to be independent and identically normally distributed $\mu_{n k} \square N\left(0, \sigma_{k}\right)$, with the variance $\sigma_{k}$ capturing the size of the correlation between alternatives in the same nest.

With regard to our data, a specification of the error components leading to the following three exclusive nests performed best in terms of model fit. The first nest comprises conventional, hybrid and natural gas vehicles. The second nest contains PHEVs and electric vehicles, whereas biofuel and hydrogen vehicles are grouped in the last nest. Even though we chose this nesting structure due to its statistical performance, this substitution pattern is also absolutely plausible, as apparently more similar vehicle alternatives or fuel types are assorted and, thus, correlated in unobserved factors. For instance, the three vehicle alternatives grouped together in the first nest are the ones exclusively running on fossil fuels. Furthermore, they are also the best-known by the potential car buyers, as they currently have the greatest market shares. In the second nest, vehicle alternatives are clustered which are exclusively electrically propelled or at least drive electrically for the most part, and, thus, share the unique and unfamiliar characteristic of having a plug. The remaining two vehicles clustered together in the third nest are both powered by liquid non-fossil fuels, namely biofuel and hydrogen, which are almost non-existent at fuel stations in Germany, resulting in a high unfamiliarity with both fuels. Additionally, hydrogen and biofuel vehicles have identical features in our experiment, which possibly made them highly substitutable from the respondents' point of view. Hence the perceived similarity between some of the fuel types (vehicles) is absolutely reasonable, as is the consequence of the correlation structure of our model, namely that more similar vehicles draw more demand from each other than from dissimilar vehicle alternatives.

Given the specified utility functions and values for $\mu_{n k}$, the conditional choice probabilities are logit as in the standard MNL model. Thus, the probability that person $n$ selects alternative $i$ can be expressed as

$$
P_{n i}=\frac{\exp \left(\beta^{\prime} x_{n i}+\sum_{k=1}^{K} \mu_{n k} d_{j k}\right)}{\sum_{j=1}^{J} \exp \left(\beta^{\prime} x_{n j}+\sum_{k=1}^{K} \mu_{n k} d_{j k}\right)} .
$$

However, since $\mu_{n k}$ is a random variable and hence not given, the (unconditional) choice probability of alternative $i$ being chosen by decision-maker $n$ is obtained by integrating the 
standard logit choice probability in eq. (3) over all values of $\mu_{n k}$, weighted by the density of $\mu_{n k}$, i.e.

$$
P_{n i}=\int_{\mu_{n 1}} \ldots \int_{\mu_{n K}} \frac{\exp \left(\beta^{\prime} x_{n i t}+\sum_{k=1}^{K} \mu_{n k} d_{j k}\right)}{\sum_{j=1}^{J} \exp \left(\beta^{\prime} x_{n j t}+\sum_{k=1}^{K} \mu_{n k} d_{j k}\right)} \phi\left(\mu_{n 1} \mid 0, \sigma_{1}\right) \ldots \phi\left(\mu_{n K} \mid 0, \sigma_{K}\right) d \mu_{n 1} \ldots d \mu_{n K} .
$$

If decision-makers are repeatedly observed in choice situations, such as in our survey, this panel effect should be taken into account. In our model, this is realized by the inclusion of individual specific error components that are constant over the $T$ choice occasions that each respondent has to face. Hence, the probability that person $n$ chooses a specific sequence of alternatives $\mathbf{i}=\left\{i_{1}, \ldots, i_{T}\right\}$ is given by the integral of the product of logit formulas, i.e.

$$
P_{n \mathrm{i}}=\int_{\mu_{n 1}} \ldots \int_{\mu_{n K}} \prod_{t=1}^{T} \frac{\exp \left(\beta^{\prime} x_{n i t}+\sum_{k=1}^{K} \mu_{n k} d_{j k}\right)}{\sum_{j=1}^{J} \exp \left(\beta^{\prime} x_{n j t}+\sum_{k=1}^{K} \mu_{n k} d_{j k}\right)} \phi\left(\mu_{n 1} \mid 0, \sigma_{1}\right) \ldots \phi\left(\mu_{n K} \mid 0, \sigma_{K}\right) d \mu_{n 1} \ldots d \mu_{n K}
$$

Unfortunately, the choice probabilities in eqs. (4) and (5) cannot be calculated exactly, as the integrals do not have a closed form. Thus, in the MXL model, the unconditional choice probabilities have to be approximated through simulation by repeatedly drawing values of $\mu_{n k}$ from their distributions, calculating the corresponding conditional choice probabilities, and averaging the results. To ensure the robustness of the results, we used 1,000 Halton draws for the maximum simulated likelihood estimation.

The variables entering the deterministic portion of utility in our model are given in Table 3 and are discussed in detail in the following. They can roughly be separated into two groups. First, the attributes used to describe the different vehicle alternatives in the discrete choice experiment, and, second, the socio-demographic characteristics of the respondents. To be more precise, the fuel types are included as alternative-specific constants (ASCs), with conventional fuel (gasoline/diesel) acting as the base alternative. ${ }^{7}$ As the findings in the

\footnotetext{
${ }^{7}$ The ASC of an alternative captures the average effect of all unobserved factors (i.e. that are not included in the model, but are associated by respondents with the 'label' of the alternative) on its utility, all else being equal. In this respect, the ASCs can be interpreted as the average preference for the respective fuel types, ceteris paribus (e.g. Train, 2003).
} 
literature are inconsistent, we do not have any specific expectations about the final order of popularity of the different propulsion technologies among respondents. However, we do anticipate specific impacts on choice probability for the respective vehicle attributes. For instance, we expect that purchase price, fuel cost, $\mathrm{CO}_{2}$ emissions, refueling time, and battery recharging time all have a negative sign, and we suppose the sign to be positive for driving range, fuel availability, and the two governmental incentives.

The vehicle attributes enter the utility functions partly as generic variables, as in the case of purchase price, fuel cost, $\mathrm{CO}_{2}$ emissions ${ }^{8}$, and fuel availability, and partly as alternativespecific variables. The latter was done for the simple reason that these attributes are only linked with particular fuel types by design, as in the case of refueling time, governmental incentives, and battery recharging time, or had specific attribute levels for some vehicle alternatives (e.g. the driving range of electric vehicles was described by unique levels) or because of content-related reasons. For example, we assume the duration of the batteryrecharging process to be more important for electric vehicles compared to PHEVs, as the former do not possess a backup propulsion technology and thus are reliant upon short charging times.

Additionally, some vehicle attributes are interacted with socio-demographic and attitudinal variables. For instance, we expect a more pronounced price sensitivity for households with low income. However, since about one fifth of the respondents did not indicate their income level, we follow the approach of Achtnicht et al. (2012) and use the respondents' stated purchase price of their current or planned vehicle as a proxy, which can be justified on the ground that both variables are highly correlated $(r=0.442)$. Thus, in the utility functions, the purchase price is additionally interacted with a dummy variable, which indicates individuals who have stated a maximum purchase price of $€ 20,000$. Moreover, the higher concern about vehicles' $\mathrm{CO}_{2}$ emissions from above-average environmentally aware car buyers is well documented in the vehicle choice literature (e.g. Ewing and Sarigöllü, 2000; Daziano and Bolduc, 2011; Achtnicht et al., 2012). On that account, we included an interaction of the $\mathrm{CO}_{2}$ emission attribute with a dummy variable that identifies the highly environmentally aware

\footnotetext{
${ }^{8}$ Although $\mathrm{CO}_{2}$ emissions are alternative-dependent by design, alternative-specific parameter estimates did not differ statistically, so that the inclusion of a single generic $\mathrm{CO}_{2}$ emissions parameter into the model is superior.
} 
consumers in our model, i.e. the $40 \%$ of individuals with the highest values on the environmental awareness scale of Preissendörfer (1999).

Furthermore, to trace the consumer groups that are open-minded about the different alternative fuels per se, we add interaction terms of the ASCs with socio-demographic and socio-economic characteristics of the respondents. In other words, we expect the stated preferences to differ for the different fuel types dependent on the respondents' age, educational level, environmental awareness, access to an electric socket, share of city trips, and car segment. For example, based on previous studies (e.g. Potoglou and Kanaroglou, 2007; Ziegler, 2012), we anticipate that younger, well-educated, and environmentally aware car buyers are more impartial towards at least some of the alternative fuels, and that the possibility to plug-in the car at home, a higher share of kilometers driven in urban areas, and the preference for a small car, increase the choice probabilities for electrified vehicles.

Table 3: Definition of variables used in the model

\begin{tabular}{|c|c|}
\hline Variables & Definition \\
\hline LPG/CNG & 1 if fuel type is natural gas (LPG/CNG), 0 otherwise \\
\hline Hybrid & 1 if fuel type is hybrid, 0 otherwise \\
\hline PHEV & 1 if fuel type is PHEV, 0 otherwise \\
\hline Electric & 1 if fuel type is electric, 0 otherwise \\
\hline Biofuel & 1 if fuel type is biofuel, 0 otherwise \\
\hline Hydrogen & 1 if fuel type is hydrogen, 0 otherwise \\
\hline Purchase price & Purchase price in thousands of $€$ \\
\hline Fuel cost & Fuel cost in $€$ per $100 \mathrm{~km}$ \\
\hline $\mathrm{CO}_{2}$ emissions & $\begin{array}{l}\text { Percentage of } \mathrm{CO}_{2} \text { emissions of an comparable average current vehicle } \\
\text { of the respondents' favorite car segment }\end{array}$ \\
\hline Driving range & Driving range on a full tank/battery in $\mathrm{km}$ \\
\hline Fuel availability & Percentage of filling/recharging stations with proper fuel \\
\hline Refueling time & Refueling time in minutes \\
\hline Battery recharging time & Battery recharging time in minutes \\
\hline Incentive 1 (No vehicle tax) & 1 if incentive is granted, 0 otherwise \\
\hline Incentive 2 (Free parking and bus lane access) & 1 if incentive is granted, 0 otherwise \\
\hline Stated purchase price $<€ 20,000$ & 1 if respondent stated to spend $€ 20,000$ at most, 0 otherwise \\
\hline Age $<44$ years & 1 if respondent is younger than 44 years of age, 0 otherwise \\
\hline High environmental awareness & $\begin{array}{l}1 \text { if respondent is more environmentally aware than } 60 \% \text { of the sample, } \\
0 \text { otherwise }\end{array}$ \\
\hline Parking lot equipped with socket & $\begin{array}{l}1 \text { if respondent has access to a parking lot equipped with a socket, } 0 \\
\text { otherwise }\end{array}$ \\
\hline Share of city trips $>60 \%$ & $\begin{array}{l}1 \text { if respondents' share of city trips on overall annual trips is greater } \\
\text { than } 60 \%, 0 \text { otherwise }\end{array}$ \\
\hline High educational level & $\begin{array}{l}1 \text { if respondent has higher education entrance qualification or university } \\
\text { (of applied sciences) degree, } 0 \text { otherwise }\end{array}$ \\
\hline Car segment mini or small & $\begin{array}{l}1 \text { if respondent indicated the purchase of a mini or small car, } 0 \\
\text { otherwise }\end{array}$ \\
\hline
\end{tabular}


In contrast to other studies on the potential demand for AFVs (e.g. Dagsvik et al., 2002; Batley et al., 2004; Caulfield et al., 2010; Mabit and Fosgerau, 2011; Musti and Kockelman, 2011; Ziegler, 2012), we did not find significant effects of, for example, gender, the number of children or cars in the household, or the primary usage of the vehicle for journeys to work on the choice of specific fuel types during the specification of our final model.

\section{Empirical Results and Discussion}

This section describes the empirical results of the two estimated discrete choice models and the calculations of consumers' WTP for an improvement of selected vehicle attributes. In a further step, the impact of various policy scenarios on the potential demand for alternatively fueled vehicles is simulated.

\subsection{Discrete Choice Models}

The estimation results from applying both the MNL model and the MXL model are given in Table 4. In both models, all experimentally varied vehicle attributes, except refueling time, show a significant impact on the choice decision, and the estimated coefficients all have the expected sign. However, three differences between the models are salient. First, the MXL specification performs significantly better than the MNL specification, regarding model fit ${ }^{9}$. Second, although the significance level of two parameters is lower in the MXL model (Share of city trips $>60 \% \times$ Electric; High educational level $\times$ PHEV), the contrary is true for a larger number of other variables. For instance, in the error components model, three parameters become significant which are insignificant in the standard logit model (Age $<44$ years $\times$ Hybrid; High environmental awareness $\times$ LPG/CNG; Share of city trips $>60 \% \times$ Hybrid), and the significance level of three further coefficients is increased (LPG/CNG; Share of city trips $>60 \% \times$ LPG/CNG; Car segment mini or small $\times$ Hybrid). Finally, the three error components are highly significant, thus pointing towards correlation in the unobserved part of

\footnotetext{
${ }^{9}$ A likelihood ratio test illustrates that the error components specification is a statistically highly significant improvement over the MNL specification: $-2\left(L L_{M N L}-L L_{E C M}\right)=939.62>\chi_{\alpha=0.95}^{2}(3)=7.81$. This improvement in log likelihood in the MXL model is predominantly owed to the consideration of respondents' repeated choices in the estimation process, and stems only secondarily from the allowance for correlation between vehicle alternatives.
} 
utility between the respective vehicle alternatives (fuel types) in the three different nonoverlapping nests of our MXL model. Therefore, in the following detailed discussion of the estimation results, we focus on the MXL model parameters.

As expected, both of the main vehicle expense factors - purchase price and fuel cost per $100 \mathrm{~km}$ - have a negative impact on the choice decisions and both enter our model significantly. On top of that and further in line with our expectations, the results indicate that individuals who have stated a maximum purchase price of $€ 20,000$ are endued with a higher price sensitivity, as their purchase price parameter is about twice as large. ${ }^{10}$ A similar pattern can be observed for the influence that vehicles' $\mathrm{CO}_{2}$ emissions exert on respondents' stated choice. Specifically high vehicle emissions are disfavored by all car buyers in general, as shown by the strongly significant (and expectedly) negative parameter, but are rejected even more by environmentally aware consumers, as the more than twice as large coefficient suggests.

Driving range enters the model significantly and positively, as anticipated, because frequent refueling stops are time-consuming and inconvenient. It also affects the carpurchasing decision concerning electric vehicles much more strongly, compared with all other fuel types. This result was expected, since the driving range was modeled alternativedependently by design to cover for the currently exclusively short driving ranges of electric vehicles. Striking, however, is the almost doubled value of the coefficient, indicating that car buyers assign a very high value to an improvement of extremely limited driving ranges. In other words, this result supports the finding that the enhancement of the restricted cruising radius of electric vehicles is an important prerequisite for a high consumer demand. The same holds true for the density of the filling station network, as a widespread refueling infrastructure decreases the risk of being stranded with an empty tank or battery. Thus, it is not surprising that fuel availabilty impacts vehicle choice significantly and with a positive sign. Refueling time, on the other hand, does not seem to be a crucial factor during vehicle purchase decisions. This holds at least if it does not exceed the upper bound of 10 minutes (as

\footnotetext{
${ }^{10}$ The purchase price parameter for individuals with a stated purchase price of $€ 20,000$ or less results from the summing up of the general purchase price parameter and the purchase price interaction coefficient (purchase price $\times$ stated purchase price $<€ 20,000$ ).
} 
in our experimental design), since it does not enter the final model significantly although with the expected sign.

The case looks entirely different for the battery recharging time, which is highly significant and negatively signed, indicating that a prolongation of the recharging process strongly decreases the utility of the respective vehicle. Interestingly, and confirming our assumption, the magnitude of this effect is dependent on the degree of electrification of the considered vehicles. This implies that the impact of a lacking fast-charging infrastructure on the choice of a purely electric vehicle is more severe (twice as large) than for a bi-fueled PHEV. This finding also suggests that respondents correctly understood the properties of the unfamiliar drivetrain technology of PHEVs.

Governmental incentives also play an important role in vehicle choice situations, regardless of whether they are of monetary or non-monetary nature, as both positively influence vehicle demand significantly. This result indicates that the already enacted vehicle circulation tax exemption for electric vehicles in Germany is able to increase vehicle demand, and that free parking or the permission for the usage of bus lanes, both of which are currently under consideration in Germany as well, have the potential to further promote AFVs in a relatively inexpensive way. ${ }^{11}$

However, our results show that new car buyers on average hold a reservation against AFVs, which would of course be a huge barrier to their extensive diffusion. To be more

\footnotetext{
${ }^{11}$ The annual circulation tax in Germany is calculated depending on the fuel type (see e.g. BMF, 2011), so that conventionally fueled vehicles are burdened on the basis of the engine displacement (base tax rates of $€ 2 / 100 \mathrm{ccm}$ for gasoline and $€ 9.5 / 100 \mathrm{ccm}$ for diesel engines) and, additionally, the $\mathrm{CO}_{2}$ emissions (tax rate of $€ 2$ per $\mathrm{gCO}_{2} / \mathrm{km}$ for every gram above $110 \mathrm{gCO}_{2} / \mathrm{km}$ ) of the newly registered vehicle, while electric vehicles are assessed by their total weight (€5.63-6.39/200 kg, increasing with weight class). The vehicle tax exemption for electric vehicles is currently granted for 10 years. Thus, for example, compared to an average conventionally fueled vehicle (e.g. 1,600 ccm and $140 \mathrm{gCO}_{2} / \mathrm{km}$ ) purchased otherwise, the vehicle tax savings over the entire lifetime of ten years would amount to €920-2,120 (depending on the fuel), or compared to a regularly taxed electric vehicle $(1,500 \mathrm{~kg})$ to $€ 450$. Regarding the possibility to use parking lots free of charge, the lifetime savings would amount to at least $€ 300$ (the annual average cost for a resident parking permit in German cities is about €30), depending on the additional usage frequency of parking lots in foreign cities. Both incentives, however, would reside at the lower end of comparable purchase price premiums that are currently granted for electric vehicles in some European countries.
} 
precise, we estimated an MXL model without interactions between the ASCs and sociodemographic and attitudinal dummy variables (not reported in this paper), to gain an undistorted picture of the general acceptance of the different fuel types in the German population. Since all fuel type coefficients have a negative sign and are highly significant, alternative fuels on average seem to be less preferred compared to conventional fuels, which is the base alternative, with electric vehicles being valued most negatively.

Fortunately, this general and partially very high reluctance is mitigated in some consumer groups, as indicated in Table 4, by the significant interaction terms between the sociodemographic variables and the different ASCs. More precisely, these consumer groups can be described by age, educational level, environmental awareness, preferred vehicle segment, availability to plug in a vehicle at home, and amount of car trips in an urban area, as in our model. For instance, the probability to choose electric or hybrid vehicles is higher for younger individuals, as revealed by the (highly) significant positive coefficients of the two corresponding interaction terms (Age $<44$ years $\times$ ASC). Thus, since younger consumers are more likely to adopt technological innovations at an early stage, this result is absolutely reasonable, especially for electric vehicles as a potentially disruptive technology.

Moreover, apart from having a more pronounced sensitivity for vehicles' $\mathrm{CO}_{2}$ emissions, environmentally aware car buyers also have an increased likelihood to purchase AFVs, regardless of the actual environmental friendliness of the respective vehicle, as revealed by the highly significant and positive interaction parameters (High environmental awareness $\times$ ASC). This result, however, is somewhat surprising. In Germany, natural gas vehicles are not primarily promoted as being 'green', e.g. in contrast to hybrid cars that also run on fossil fuels, but as being cost-effective. Biofuels, for their part, are at the center of a very controversial discussion, not only since their share in gasoline was increased from 5\% to $10 \%$ in Germany at the beginning of 2011, due to their limited capability to mitigate GHG emissions and their price-raising effects on food products (e.g. Malins, 2012; Zilberman et al., 2012). 
Table 4: Parameter estimates

\begin{tabular}{|c|c|c|c|c|}
\hline \multirow[t]{2}{*}{ Variable } & \multicolumn{2}{|c|}{ Multinomial logit } & \multicolumn{2}{|c|}{ Mixed logit } \\
\hline & Coefficient & Std. err. & Coefficient & Std. err. \\
\hline LPG/CNG & $-0.20931^{*}$ & 0.12616 & $-0.27490 * *$ & 0.11670 \\
\hline Hybrid & $-0.47973 * * *$ & 0.12391 & $-0.57398 * * *$ & 0.11992 \\
\hline PHEV & $-0.81703^{* * *}$ & 0.10022 & $-0.93585^{* * *}$ & 0.13973 \\
\hline Electric & $-1.66388 * * *$ & 0.12856 & $-1.84035^{* * *}$ & 0.14752 \\
\hline Biofuel & $-0.77118^{* * *}$ & 0.11242 & $-0.80962 * * *$ & 0.12701 \\
\hline Hydrogen & $-0.59732 * * *$ & 0.11163 & $-0.61928 * * *$ & 0.13633 \\
\hline Purchase price & $-0.04560 * * *$ & 0.00221 & $-0.04993 * * *$ & 0.00112 \\
\hline Purchase price $\times$ Stated purchase price $<€ 20,000$ & $-0.04657 * * *$ & 0.00573 & $-0.05098 * * *$ & 0.00394 \\
\hline Fuel cost & $-0.04904 * * *$ & 0.00135 & $-0.05324^{* * *}$ & 0.00091 \\
\hline $\mathrm{CO}_{2}$ emissions & $-0.00192 * * *$ & 0.00040 & $-0.00203^{* * *}$ & 0.00043 \\
\hline $\mathrm{CO}_{2}$ emissions $\times$ High environmental awareness & $-0.00231 * * *$ & 0.00063 & $-0.00247 * * *$ & 0.00058 \\
\hline $\begin{array}{l}\text { Driving range } \times \text { Conventional, LPG/CNG, Hybrid, PHEV, } \\
\text { Biofuel, Hydrogen }\end{array}$ & $0.00079 * * *$ & 0.00005 & $0.00084 * * *$ & 0.00004 \\
\hline Driving range $\times$ Electric & $0.00148 * * *$ & 0.00018 & $0.00164 * * *$ & 0.00021 \\
\hline Fuel availability & $0.00423^{* * *}$ & 0.00036 & $0.00457 * * *$ & 0.00034 \\
\hline Refueling time & -0.00480 & 0.00460 & -0.00456 & 0.00541 \\
\hline Battery recharging time $\times$ PHEV & $-0.00041^{* * *}$ & 0.00015 & $-0.00049 * * *$ & 0.00017 \\
\hline Battery recharging time $\times$ Electric & $-0.00090 * * *$ & 0.00021 & $-0.00088 * * *$ & 0.00023 \\
\hline Incentive $1 \times$ PHEV, Electric, Biofuel, Hydrogen & $0.21869 * * *$ & 0.03145 & $0.23486 * * *$ & 0.03115 \\
\hline Incentive $2 \times$ PHEV, Electric, Biofuel, Hydrogen & $0.15210 * * *$ & 0.03173 & $0.16370 * * *$ & 0.03354 \\
\hline Age $<44$ years $\times$ LPG $/ C N G$ & -0.05221 & 0.10825 & -0.05065 & 0.10135 \\
\hline Age $<44$ years $\times$ Hybrid & 0.13580 & 0.10700 & $0.18529 *$ & 0.10199 \\
\hline Age $<44$ years $\times$ PHEV & -0.06536 & 0.08114 & -0.04682 & 0.11686 \\
\hline Age $<44$ years $\times$ Electric & $0.40460^{* * *}$ & 0.09316 & $0.45415^{* * *}$ & 0.11566 \\
\hline Age $<44$ years $\times$ Biofuel & -0.06804 & 0.09376 & -0.07333 & 0.10811 \\
\hline Age $<44$ years $\times$ Hydrogen & 0.00164 & 0.09449 & 0.00856 & 0.11945 \\
\hline High environmental awareness $\times$ LPG/CNG & 0.16831 & 0.11122 & $0.22530 * *$ & 0.10440 \\
\hline High environmental awareness $\times$ Hybrid & $0.44350 * * *$ & 0.10862 & $0.51088 * * *$ & 0.10184 \\
\hline High environmental awareness $\times$ PHEV & $0.71516 * * *$ & 0.08463 & $0.86580^{* * *}$ & 0.12694 \\
\hline High environmental awareness $\times$ Electric & $0.64447 * * *$ & 0.09501 & $0.78143^{* * *}$ & 0.12409 \\
\hline High environmental awareness $\times$ Biofuel & $0.36181^{* * *}$ & 0.09729 & $0.44600^{* * *}$ & 0.11392 \\
\hline High environmental awareness $\times$ Hydrogen & $0.30490 * * *$ & 0.09865 & $0.37920 * * *$ & 0.12465 \\
\hline Parking lot equipped with socket $\times$ LPG/CNG & -0.07103 & 0.10715 & -0.07143 & 0.09757 \\
\hline Parking lot equipped with socket $\times$ Hybrid & 0.06376 & 0.10560 & 0.07386 & 0.09875 \\
\hline Parking lot equipped with socket $\times$ PHEV & $0.28682 * * *$ & 0.08022 & $0.34321^{* * *}$ & 0.11782 \\
\hline Parking lot equipped with socket $\times$ Electric & $0.23410^{* *}$ & 0.09101 & $0.29191^{* *}$ & 0.11357 \\
\hline Parking lot equipped with socket × Biofuel & 0.12364 & 0.09255 & 0.14218 & 0.10884 \\
\hline Parking lot equipped with socket $\times$ Hydrogen & 0.03386 & 0.09345 & 0.04531 & 0.11515 \\
\hline Share of city trips $>60 \% \times$ LPG/CNG & $-0.29337 * *$ & 0.14868 & $-0.38150 * * *$ & 0.14159 \\
\hline Share of city trips $>60 \% \times$ Hybrid & -0.21789 & 0.14554 & $-0.28813^{* *}$ & 0.13401 \\
\hline Share of city trips $>60 \% \times$ PHEV & -0.04638 & 0.10832 & -0.05329 & 0.16098 \\
\hline Share of city trips $>60 \% \times$ Electric & $0.35730 * * *$ & 0.11733 & $0.36854 * *$ & 0.15236 \\
\hline Share of city trips $>60 \% \times$ Biofuel & -0.03488 & 0.12486 & -0.07381 & 0.14212 \\
\hline Share of city trips $>60 \% \times$ Hydrogen & -0.09827 & 0.12762 & -0.15454 & 0.14939 \\
\hline High educational level × LPG/CNG & -0.01612 & 0.10637 & -0.00085 & 0.09904 \\
\hline High educational level $\times$ Hybrid & 0.00005 & 0.10479 & 0.04065 & 0.09900 \\
\hline High educational level $\times$ PHEV & $0.24094 * * *$ & 0.07984 & $0.28753^{* *}$ & 0.11986 \\
\hline High educational level $\times$ Electric & -0.03441 & 0.09015 & 0.01308 & 0.11734 \\
\hline High educational level $\times$ Biofuel & $0.33700^{* * *}$ & 0.09228 & $0.38516^{* * *}$ & 0.10911 \\
\hline High educational level $\times$ Hydrogen & 0.09212 & 0.09291 & 0.11088 & 0.11757 \\
\hline Car segment mini or small $\times$ LPG/CNG & -0.19323 & 0.12839 & -0.18776 & 0.12743 \\
\hline Car segment mini or small $\times$ Hybrid & $-0.23917^{*}$ & 0.12720 & $-0.25898 * *$ & 0.11439 \\
\hline Car segment mini or small $\times$ PHEV & -0.01650 & 0.09505 & 0.01909 & 0.15523 \\
\hline Car segment mini or small $\times$ Electric & $0.43300^{* * *}$ & 0.10350 & $0.47736^{* * *}$ & 0.14405 \\
\hline Car segment mini or small $\times$ Biofuel & 0.05272 & 0.10910 & 0.05960 & 0.13066 \\
\hline Car segment mini or small $\times$ Hydrogen & -0.03763 & 0.11083 & -0.04626 & 0.14045 \\
\hline \multicolumn{5}{|l|}{ Error components } \\
\hline$\sigma_{1}$ (Conventional, LPG/CNG, Hybrid) & & & $0.74401^{* * *}$ & 0.04540 \\
\hline$\sigma_{2}$ (PHEV, Electric) & & & $0.84178^{* * *}$ & 0.04252 \\
\hline$\sigma_{3}$ (Biofuel, Hydrogen) & & & $0.33329 * * *$ & 0.09388 \\
\hline Persons (Choices) & \multicolumn{2}{|c|}{711 (10665) } & \multicolumn{2}{|c|}{711 (10665) } \\
\hline Log likelihood & \multicolumn{2}{|c|}{-12637.94} & \multicolumn{2}{|c|}{-12168.13} \\
\hline$\rho^{2}(0)$ & \multicolumn{2}{|c|}{0.391} & \multicolumn{2}{|c|}{0.414} \\
\hline$\rho^{2}(\mathrm{c})$ & \multicolumn{2}{|c|}{0.108} & \multicolumn{2}{|c|}{0.141} \\
\hline
\end{tabular}

Note: Statistical significance is displayed as $* * * p<0.01, * * p<0.05$, and $* p<0.1$; Incentive $1=$ No vehicle tax; Incentive $2=$ Free parking and bus lane access 
Less surprising and absolutely reasonable is the elevated choice probability for PHEVs and electric vehicles, when consumers at home have access to a parking lot equipped with a socket, as suggested by the positively signed and highly significant interaction terms (Parking lot equipped with socket $\times$ ASC), since the charging infrastrucutre is sparse at present. This finding may further point to a sort of discomfort or uncertainty regarding public charging (e.g. risk of vandalism or of being left without the possibility to plug-in/recharge the battery).

Furthermore, the demand for natural gas and hybrid vehicles is lower for individuals who predominantly use their car for city trips, while they are more likely to buy an electric vehicle (Share of city trips $>60 \% \times$ ASC). A possible explanation for this finding might be the existing notion of current electric vehicles being limited in range, which is why they are also promoted as city cars, and natural gas and hybrid vehicles being very fuel-efficient and, thus, cost-effective.

The probability of purchasing a PHEV or a biofuel vehicle, on the other hand, increases with the educational level of car buyers (High educational level $\times$ ASC). Finally, car segment is also a relevant attribute in fuel type choice, as the significant interaction coefficients show (Car segment mini or small $\times$ ASC). While consumers who indicated the purchase of a small vehicle are also more likely to choose an electric vehicle, the contrary is true for hybrid vehicles. A reason for this might be the aforementioned city car image of electric vehicles, and the fact that hybrid drivetrains are currently predominantly used in larger-sized vehicles.

In a next step, we also compare our estimation results with the findings of related previous vehicle choice studies reported in section 1. Concerning the impact (direction and significance) of purchase price, fuel cost, driving range, fuel availability, refueling and recharging time, as well as $\mathrm{CO}_{2}$ emissions on vehicle choice, our results are to a large extent in line with the literature. In contrast, however, our findings on the influence of governmental incentives on vehicle demand differ somewhat. Specifically, while our results with respect to tax exemptions are in line with those reported in Potoglou and Kanaroglou (2007), they differ concerning the deliverance of parking fees and the access to high occupancy lanes with one passenger, as these are found to be insignificant in their study. On the other hand, Horne et al. (2005) found that access to express lanes increases the choice probability significantly, which is analogous to our results for the significant positive influence of a bus lane usage permission on vehicle preferences. Looking at the acceptance of the different alternative fuels both in general and across consumer groups, the picture becomes even more fuzzy. Our result of a 
general preference for conventional fuel vehicles among German car buyers is in line with the findings of Achtnicht (2012) and Ziegler (2012) and is also in accord with the results of Ahn et al. (2008) for South Korea, while it differs from the results of Dagsvik (2002) for Norway, Batley (2004) for the UK, Mabit and Fosgerau (2011) for Denmark, Ewing and Sarigöllü (2000), Mau et al. (2008) and Axsen et al. (2009) for Canada, as well as Musti and Kockelman (2011) for the US, who all find a higher stated preference for the respective alternative fuels under consideration. Furthermore, our result is partly distinct from the findings of Horne et al. (2005) for Canada, as they report a higher choice probability for hydrogen and hybrid, but also a lower preference for alternative fuel compared to gasoline vehicles, and of Brownstone and Train (1999) and Brownstone et al. (2000), respectively, who reveal a higher stated preference for methanol and CNG, but also a lower preference for electric compared to gasoline vehicles in their Californian survey.

Turning to the individual characteristics of the respondents and their influence on car purchase decisions, our findings again partially deviate from those of other studies. While our results of a positive impact of respondents' environmental awareness on the preference for AFVs are broadly comparable to the findings of Ewing and Sarigöllü (2000), Batley et al. (2004), Hidrue et al. (2011), Ziegler (2012), and Achtnicht et al. (2012), which are the only studies taking this attitudinal effect into account, this unanimity is non-existent with respect to the impact of age on fuel type choice. Thus, while our finding of young and middle-aged consumers being oriented towards electric vehicles matches with those of Hidrue et al. (2011), Ziegler (2012), and Achtnicht et al. (2012), our result of age negatively influencing the preference for hybrid vehicles is diametrically opposed to the finding of Musti and Kockelman (2011). Regarding the relationship of the preferred car size of the respondents on their fuel type choice, the case is quite similar, i.e. our findings that buyers of small cars are more likely to purchase an electric vehicle are comparable to those of Hidrue et al. (2011), but concerning their decreased likelihood of choosing a hybrid vehicle they are contrary to those of Caulfield et al. (2010). The findings of Hidrue et al. (2011) are corroborated by our result of a positive effect of a home parking lot equipped with a socket on the choice probability of (plug-in hybrid ) electric vehicles. Finally, although going in the same direction of a positive influence of consumers' education on the preference for AFVs, our results contradict those of Brownstone and Train (1999), Brownstone et al. (2000), Hidrue et al. (2011), and Potoglou 
and Kanaroglou (2007), as they all find an increased choice of electric or hybrid vehicles with educational level, instead of PHEVs and biofuel vehicles.

Summing up, leaving aside the differences regarding the vehicle attributes and fuel alternatives considered in the mentioned studies aside for the time being, it seems that German car buyers at present are comparatively reluctant toward AFVs, which could be problematic in terms of AFVs' fast and successful diffusion, and specifically applies to electric cars, the least preferred vehicle alternative. However, the results also show that some consumers are more sensitive to new vehicle technologies and fuel types than others. In other words, the most promising target group for the adoption of all kinds of AFVs are younger, well-educated, and environmentally aware car buyers, who also have the possibility to plug in the car at home, in case the next car has an electrified drivetrain, while for the diffusion of hybrid and electric vehicles, the respective car segment should also be taken into account. Additionally, marketing should focus on drivers with a higher share of urban trips to accelerate the demand for electric vehicles, or on consumers who mostly drive on highways to speed up the adoption of hybrid and natural gas vehicles. Still, a prerequisite for a purchase decision in favor of AFVs is that their characteristics become competitive to those of conventionally fueled vehicles, because our estimation results show that, except for refueling time, all considered monetary and non-monetary vehicle attributes significantly influence vehicle choice. This statement also holds for the aforementioned very AFV-friendly consumers.

\subsection{Willingness-to-pay for vehicle attributes}

The monetary value, and thus the importance that car buyers ascribe to the diverse vehicle features can be quantified by measuring their respective WTP. The WTP is the maximum monetary amount that an individual is willing to pay for a marginal improvement of another commodity (here: vehicle attribute), leaving the level of utility unchanged. Based on the estimation results in Table 4, the WTP is calculated as the ratio of the coefficient of a specific vehicle attribute and the coefficient of the purchase price, holding everything else constant. Consumers' marginal WTP for improvements of the most important vehicle characteristics is shown in Table 5. As can be seen, individuals with a stated purchase price below $€ 20,000$ are willing to pay only half as much for beneficial changes in other vehicle features, compared to respondents who indicated the purchase of a more expensive car. This finding reflects their markedly larger price sensitivity (purchase price parameter value) and the greater importance 
of the vehicle price during the purchase decision in relation to other vehicle features, due to the much more pronounced budget constraints of this consumer group. Nevertheless, the calculated WTP values for the remaining vehicle attributes are considerable, even for consumers with lower stated purchase prices.

Depending on the targeted price range of their next vehicle, car buyers are willing to expend between approximately $€ 530$ and $€ 1,070$ for fuel cost savings of $€ 1$ per $100 \mathrm{~km}$. This result indicates that the average German driver with an annual mileage of about $15,000 \mathrm{~km}$ is willing to accept a payback period of around 3.5 to 7 years for an investment in fuel consumption reduction measures. This finding is reasonable, as it covers the medium vehicle duration of possession of 6-7 years (DAT, 2012). This holds true all the more for drivers with higher annual mileages, for whom the amortization period of fuel economy improvements diminishes even further. Our findings are also in line with those of Batley et al. (2004), who report a WTP of $£ 334$ for a 1p/mile reduction in operating costs, which can be translated into a WTP of $€ 538$ for fuel cost savings of $€ 1 / 100 \mathrm{~km}$, applying an exchange rate of $£ 1=€ 1.23$.

Table 5: Marginal WTP for changes in selected vehicle attributes

\begin{tabular}{lcc}
\hline & $\begin{array}{c}\text { Stated purchase } \\
\text { price }>\mathbf{€ 2 0 , 0 0 0}\end{array}$ & $\begin{array}{c}\text { Stated purchase } \\
\text { price }<\mathbf{€ 2 0 , 0 0 0}\end{array}$ \\
\hline Fuel cost reduction of $€ 1 / 100 \mathrm{~km}$ & $1,066.38$ & 527.63 \\
$\mathrm{CO}_{2}$ emissions abatement of $1 \% \times$ Low environmental awareness & 40.71 & 20.14 \\
$\mathrm{CO}_{2}$ emissions abatement of $1 \% \times$ High environmental awareness & 90.24 & 44.65 \\
Driving range increase of $1 \mathrm{~km} \times$ Conventional, LPG/CNG, Hybrid, & 16.82 & 8.32 \\
PHEV, Biofuel, Hydrogen & & 16.21 \\
Driving range increase of $1 \mathrm{~km} \times$ Electric & 32.76 & 45.32 \\
Fuel availability increase of $1 \%$ & 91.59 & 4.84 \\
Battery recharging time reduction of 1 min $\times$ PHEV & 9.78 & 8.70 \\
Battery recharging time reduction of 1 min $\times$ Electric & 17.58 & $2,327.53$ \\
Incentive 1 (No vehicle tax) & $4,704.07$ & $1,622.30$ \\
Incentive 2 (Free parking and bus lane access) & $3,278.76$ & \\
\hline
\end{tabular}

The WTP to abate $1 \%$ of the $\mathrm{CO}_{2}$ emissions of a current average car ranges from about $€ 20$ to $€ 40$ and from $€ 45$ to $€ 90$, depending on the budget and the environmental awareness of the respondent. In other words, environmentally aware consumers are willing to pay twice as much for an emissions reduction as environmentally unaware consumers are, all else equal. Additionally, we can see that environmentally conscious consumers with lower stated vehicle purchase prices still appraise an emissions reduction higher than less environmentally concerned individuals without this $€ 20,000$ budget constraint, and thus are willing to pay more for it. Our results are comparable but slightly different to the values of Batley et al. 
(2004), Potoglou and Kanaroglou (2007), Hidrue et al. (2011), and Achtnicht (2012). For instance, Batley et al. (2004) report the WTP of a $10 \%$ reduction in vehicles' $\mathrm{CO}_{2}$ emissions amounting to about $£ 700$ (€860) in the UK, while Mabit and Fosgerau (2011) find a WTP of Danish respondents of approximately $€ 4,230$ to $€ 5,700$ for halving the vehicle pollution. Both are thus in line with our findings in the case of environmentally aware consumers without a $€ 20,000$ purchase price bound. Potoglou and Kanaroglou (2007), on the other hand, reveal that Canadians are willing to expend between $\$ 2,030$ and $\$ 4,820$ (€1,540 to $€ 3,660$ ) if their next vehicle would emit only $10 \%$ of a present day average car, and Hidrue et al. (2011) report a WTP of $\$ 1,940$ to $\$ 4,350(€ 1,470$ to $€ 3,310)$ for a pollution reduction of $50 \%$ and 95\% in the US, respectively, applying an exchange rate of $\$ 1=€ 0.76$ for Canadian and US dollars. Both correspond to the values we calculated for the group of less environmentally aware consumers. Finally, Achtnicht (2012) finds that German car buyers are willing to pay $€ 13$ to $€ 45$ and $€ 37$ to $€ 127$ per gram $\mathrm{CO}_{2} / \mathrm{km}$ emissions reduction, respectively, depending on their purchase price range. This partially exceeds our results when translated to a percentage rating scale. However, it should be noted that these WTP values concerning emission reduction measures have to be particularly interpreted with caution, as respondents of stated preference surveys that contain an environmental component are prone to the social desirability bias, i.e. the tendency to present oneself in a favorable manner with regard to social norms (see e.g. Nunnally and Bernstein, 1994), leading to an over-reporting of their 'greenness' compared to actual behavior.

For every kilometer of additional driving range, respondents are willing to pay a markup of between $€ 8$ to $€ 17$ and $€ 16$ to $€ 33$ when purchasing a non-electric and an electric vehicle, respectively, indicating the twice as high importance of an expansion of the currently short electrically propelled operating radius. Our findings for non-electric vehicles are more in accordance with the result of Batley et al (2004), who reveal a WTP of about $£ 2,100(€ 2,580)$ for a range extension of $161 \mathrm{~km}$. In regards of the WTP for an increase in driving range of electric vehicles, our results are more in line with those of Mabit and Fosgerau (2011), who state a WTP of €3,950 for the same cruising radius extension of $161 \mathrm{~km}$, and Hidrue et al. (2011), who report a WTP from $\$ 5,650$ to $\$ 12,780$ ( $€ 4,290$ to $€ 9,710$ ) for a driving range expansion from 75 miles to 300 miles (121 km to $483 \mathrm{~km}$ ), respectively.

The WTP for a $1 \%$ expansion of the refueling infrastructure of the corresponding fuel approximately comes to lie between $€ 45$ to $€ 92$. This WTP interval is, on average, 
considerably lower than the amount of $€ 70$ to $€ 820$ reported in Achtnicht et al. (2012) - also for an increase in fuel availability by one percentage point - and, albeit to a lesser extent, lower than the WTP of $£ 1,100(€ 1,350)$ for a $10 \%$ increase in fuel availability found by Batley et al. (2004), suggesting that respondents' vehicle choice in our study was not as strongly influenced by fuel availability rates.

Consumers are willing to pay between about $€ 5$ to $€ 18$ for every saved minute in battery recharging time, depending on their stated purchase price and the drivetrain technology (PHEV or fully electric vehicle). What can be seen is that respondents are willing to spend much higher amounts for a decrease in recharging time for purely electric vehicles, which is reasonable, as these do not have a backup propulsion technology like PHEVs and, thus, strongly depend on short recharging periods. We find that a charging time reduction from 6 hours to 10 minutes would be worth from about $€ 1,750$ to $€ 3,500$ for PHEVs and $€ 3,150$ to $€ 6,300$ for electric vehicles. The latter WTP values are in line with the results of Hidrue et al. (2011), who state a WTP of between $\$ 2,140$ and $\$ 8,570$ (€1,630 and $€ 6,510$ ) for a decrease in the charging time of electric vehicles from 10 hours to 5 hours or to 10 minutes, respectively. The findings are also partly supported by Ito et al. (2013), who report a WTP for battery exchange stations (reduction of the recharging time form 8 hours to 5 minutes) of $¥ 679,000$ (€6,110, applying an exchange rate of $¥ 1=€ 0.009$ ), but only of $¥ 73,000$ (€660) for a quick recharging possibility at home that decreases the recharging process from 8 hours to 30 minutes.

Car buyers are willing to pay considerable amounts for the two different governmental incentives considered in our study. For instance, their WTP for a vehicle circulation tax exemption over the entire lifetime of the vehicle ranges between approximately €2,330 and $€ 4,700$. For an assumed lifetime of the vehicle of 10 years, these values appear to be realistic, although rather for larger-sized diesel cars (see footnote 11 for an exemplary calculation), and are in line with those of Potoglou and Kanaroglou (2007), who reveal a WTP from \$2,100 to $\$ 4,990$ ( $€ 1,600$ to $€ 3,790$ ) for tax-free vehicles. Furthermore, the WTP for the possibility to park free of charge and the allowance to use bus lanes amounts to between $€ 1,620$ and $€ 3,280$ which are quite substantial WTP amounts. However, they are comparable to those of Horne et al. (2005), who find a WTP of $\$ 1,780$ (€1,350) for express lane access alone.

In summary, it can be stated that German car buyers seem to value improvements in the most important vehicle features equally to consumers in other countries and are willing to pay 
considerable amounts for this purpose. However, for a translation of these findings into realistic potential vehicle demand forecasts, or for an assessment of the effects that changes in vehicle attributes might have on future market shares of the different fuel types, the parameter estimates in Table 4 have to be coupled with current and actual data on vehicle attributes or scenarios of their levels in the future.

\subsection{Scenario Simulations}

In order to determine realistic market shares of conventional and alternative propulsion technologies with the aid of our model coefficients, we first have to describe the German vehicle market conditions in a representative manner. This status quo or base case is shown in Table 6 and is derived by defining an average car for each drivetrain tochnology or fuel type based on current market data or discounted expected values, i.e. for hydrogen, but partly also for PHEVs and electric vehicles, reported in the literature (ADAC, 2012a; ADAC, 2012b; ADAC, 2012c; ADAC, 2012d; BMWi, 2012; CEP, 2012; Daziano and Achtnicht, 2012; Grüning et al., 2011; McKinsey, 2010; and Wietschel and Brüning, 2010). The base case scenario also displays the present situation in Germany concerning governmental incentives and fuel availability, as today only electric vehicles are tax-exempt and other beneficial legislations have not yet been enacted, and since the service station density varies substantially by fuel type (see footnote 5 ).

Table 6: Specification of the base case scenario

\begin{tabular}{|c|c|c|c|c|c|c|c|c|c|}
\hline & $\begin{array}{c}\text { Purchase } \\
\text { price (€) }\end{array}$ & $\begin{array}{c}\text { Fuel } \\
\text { cost } \\
(€)\end{array}$ & $\begin{array}{c}\mathrm{CO}_{2} \\
\text { emissions } \\
(\%)\end{array}$ & $\begin{array}{c}\text { Driving } \\
\text { range } \\
(\mathbf{k m})\end{array}$ & $\begin{array}{c}\text { Fuel } \\
\text { availability } \\
(\%)\end{array}$ & $\begin{array}{c}\text { Refueling } \\
\text { time } \\
\text { (min) }\end{array}$ & $\begin{array}{c}\text { Battery } \\
\text { recharging } \\
\text { time (min) }\end{array}$ & $\begin{array}{c}\text { Incentive } \\
1\end{array}$ & $\begin{array}{c}\text { Incentive } \\
2\end{array}$ \\
\hline Conventional & 21,800 & 9.0 & 100 & 1,000 & 100 & 5 & & & \\
\hline LPG/CNG & 23,900 & 6.5 & 84 & 1,000 & 50.9 & 5 & & & \\
\hline Hybrid & 26,700 & 7.5 & 77 & 1,000 & 100 & 5 & & & \\
\hline PHEV & 30,200 & 5.5 & 31 & 750 & 43.3 & 5 & 240 & no & no \\
\hline Electric & 36,800 & 4.0 & 0 & 175 & 14.1 & & 480 & no & yes \\
\hline Biofuel & 22,900 & 9.0 & 23 & 750 & 2.3 & 5 & & no & no \\
\hline Hydrogen & 33,800 & 7.5 & 0 & 750 & 0.2 & 5 & & no & no \\
\hline
\end{tabular}

The main focus of our scenario analysis, however, is the description of the impact that different policy decisions or actions of the automotive industry could have on the adoption of AFVs in general and electrified vehicles in particular, as the latter are a cornerstone of future individual mobility concepts in Germany. In total, we consider nine different scenarios, 
distinguishable by the level of governmental intervention and subsidization or by the size of the steps taken by the car manufacturers, while holding all other attributes constant at their base levels. A more detailed illustration of the scenarios is provided in the following.

In addition to the aforementioned base case scenario, we examine the influence of an expansion of governmental incentives (i.e. vehicle circulation tax exemption, bus lane access, and free parking) for PHEVs, electric, and hydrogen cars, on the vehicle market in the second scenario. In scenario three, we analyze the effect that purchase premiums of $€ 5,000$ for electric and hydrogen vehicles and €2,500 for PHEVs have on vehicle demand, while we look at an even stronger decline of prices in the fourth scenario, resulting in an identical purchase price of $€ 21,800$ for all vehicles. The two scenario results give a sense of the effectiveness of governmental purchase price subsidies, as currently granted in many countries worldwide, or of price decreases, e.g. due to technical innovations or economies of scale in the vehicle production in general, and battery and fuelcell production in particular. In the fifth scenario, we consider the influence of battery leasing contracts, as presently offered by some car manufacturers to promote electric vehicles, on their market share. Based on available average leasing contracts, we assume a monthly fee of $€ 80$ for an annual mileage of 10,000 km, which equals to $€ 9.6 / 100 \mathrm{~km}$ in additional fuel cost, and an according purchase price reduction of $€ 10,000$, resulting in a remaining surcharge of $€ 5,000$ for the purchase of electric vehicles. A substantial increase in the cruising radius of electric vehicles to $750 \mathrm{~km}$, e.g. due to disruptive technological innovations that leave all other vehicle attributes unchanged, and its impact on vehicle choice decisions is studied in scenario 6 . In scenario 7, we look at the consequences that an expansion of the service station infrastructure to $100 \%$ for all alternative fuels has on their choice probability. A massive reduction of the battery recharging time to 5 minutes, making the length of the charging process comparable to the duration of refueling stops, and its effect on the demand for electrified vehicles is regarded in scenario 8. With this we can assess whether the higher investment costs for fast-charging or battery swapping stations are justifiable. Finally, in scenario 9, we consider a combination of scenarios 2, 3, 7, and 8, i.e. governmental monetary and non-monetary incentives and the provision of an area-wide refueling and fast-charging infrastructure, in order to get an impression about the influence of a concerted action of the administration and the private sector (as to the configuration of the service station network) on the market shares of the different propulsion technologies. 
The market shares of the different fuel types are calculated based on our sample, i.e. the actual distribution of socio-economic characteristics among respondents, and the model coefficients given in Table 5. Furthermore, the choice situation underlying the simulations is modeled as being unrestricted, so that, for each individual, one single choice set is assumed, in which all seven vehicle alternatives (fuel types) are available, and represented by the attribute levels of the respective scenario. The choice probabilities of the different propulsion technologies in the different scenarios are first calculated on an individual level and then averaged to obtain sample values (using 15000 draws). The predicted market shares of the different fuel types in the base case (scenario 1) and the other eight distinct scenarios are reported in Table 7.

Beginning with the base case, we see that conventional vehicles capture about one third of the market and that the market shares of natural gas and hybrid vehicles amount to approximately $20 \%$ and $18 \%$, respectively. Biofuels and PHEVs are chosen by about $11-12 \%$ of the (potential) car buyers, while hydrogen and electric vehicles are the most preferred option for only about $6 \%$ and $2 \%$ of the vehicle adopters, respectively.

Table 7: Simulated market shares subject to the different scenarios and their relative changes compared to the base case in parentheses (in \%)

\begin{tabular}{|c|c|c|c|c|c|c|c|c|c|}
\hline & \multicolumn{9}{|c|}{ Scenario no. } \\
\hline & $1^{*}$ & 2 & 3 & 4 & 5 & 6 & 7 & 8 & 9 \\
\hline Conventional & 30.35 & $\begin{array}{c}27.01 \\
(-11.00)\end{array}$ & $\begin{array}{c}28.89 \\
(-4.81)\end{array}$ & $\begin{array}{c}23.14 \\
(-23.76)\end{array}$ & $\begin{array}{c}30.19 \\
(-0.53)\end{array}$ & $\begin{array}{c}29.58 \\
(-2.54)\end{array}$ & $\begin{array}{c}25.74 \\
(-15.19)\end{array}$ & $\begin{array}{c}29.79 \\
(-1.85)\end{array}$ & $\begin{array}{c}21.39 \\
(-29.52)\end{array}$ \\
\hline LPG/CNG & 17.82 & $\begin{array}{c}15.83 \\
(-11.17)\end{array}$ & $\begin{array}{c}16.96 \\
(-4.83)\end{array}$ & $\begin{array}{c}16.01 \\
(-10.16)\end{array}$ & $\begin{array}{c}17.74 \\
(-0.45)\end{array}$ & $\begin{array}{c}17.37 \\
(-2.53)\end{array}$ & $\begin{array}{c}18.87 \\
(+5.89)\end{array}$ & $\begin{array}{c}17.49 \\
(-1.85)\end{array}$ & $\begin{array}{c}15.64 \\
(-12.23)\end{array}$ \\
\hline Hybrid & 20.08 & $\begin{array}{c}17.34 \\
(-13.65)\end{array}$ & $\begin{array}{l}18.79 \\
(-6.42)\end{array}$ & $\begin{array}{c}20.60 \\
(+2.59)\end{array}$ & $\begin{array}{c}19.92 \\
(-0.80)\end{array}$ & $\begin{array}{l}19.21 \\
(-4.33)\end{array}$ & $\begin{array}{c}16.87 \\
(-15.99)\end{array}$ & $\begin{array}{c}19.45 \\
(-3.14)\end{array}$ & $\begin{array}{c}13.03 \\
(-35.11)\end{array}$ \\
\hline PHEV & 10.85 & $\begin{array}{c}13.83 \\
(+27.47)\end{array}$ & $\begin{array}{c}12.23 \\
(+12.72)\end{array}$ & $\begin{array}{c}14.38 \\
(+32.53)\end{array}$ & $\begin{array}{c}10.77 \\
(-0.74)\end{array}$ & $\begin{array}{c}10.34 \\
(-4.70)\end{array}$ & $\begin{array}{c}11.73 \\
(+8.11)\end{array}$ & $\begin{array}{c}11.75 \\
(+8.29)\end{array}$ & $\begin{array}{c}18.08 \\
(+66.64)\end{array}$ \\
\hline Electric & 2.24 & $\begin{array}{c}2.26 \\
(+0.89)\end{array}$ & $\begin{array}{c}3.02 \\
(+34.82)\end{array}$ & $\begin{array}{c}4.86 \\
(+116.96)\end{array}$ & $\begin{array}{c}2.83 \\
(+26.34)\end{array}$ & $\begin{array}{c}5.45 \\
(+143.30)\end{array}$ & $\begin{array}{c}2.77 \\
(+23.66)\end{array}$ & $\begin{array}{c}3.28 \\
(+46.43)\end{array}$ & $\begin{array}{c}5.47 \\
(+144.20)\end{array}$ \\
\hline Biofuel & 12.47 & $\begin{array}{c}15.86 \\
(+27.19)\end{array}$ & $\begin{array}{c}11.68 \\
(-6.34)\end{array}$ & $\begin{array}{c}9.82 \\
(-21.25)\end{array}$ & $\begin{array}{c}12.39 \\
(-0.64)\end{array}$ & $\begin{array}{c}12.07 \\
(-3.21)\end{array}$ & $\begin{array}{c}16.00 \\
(+28.31)\end{array}$ & $\begin{array}{c}12.19 \\
(-2.25)\end{array}$ & $\begin{array}{c}12.65 \\
(+1.44)\end{array}$ \\
\hline Hydrogen & 6.19 & $\begin{array}{c}7.87 \\
(+27.14)\end{array}$ & $\begin{array}{c}8.43 \\
(+36.19)\end{array}$ & $\begin{array}{c}11.19 \\
(+80.78)\end{array}$ & $\begin{array}{c}6.16 \\
(-0.48)\end{array}$ & $\begin{array}{c}5.98 \\
(-3.39)\end{array}$ & $\begin{array}{c}8.02 \\
(+29.56)\end{array}$ & $\begin{array}{c}6.05 \\
(-2.26)\end{array}$ & $\begin{array}{c}13.74 \\
(+121.97)\end{array}$ \\
\hline
\end{tabular}

Note: * base case scenario 
In scenario 2, we look at governmental monetary and non-monetary incentives granted for all vehicles that (mostly) run on non-fossil fuels, i.e. PHEVs, electric vehicles, and cars fueled with biofuel or hydrogen, while all other attribute values are equal to those in the base case scenario. Such a policy intervention increases the choice probability for biofuel and hydrogen vehicles as well as PHEVs by approximately 27\%, and electric cars by less than $1 \%$, compared to the base case, while the market shares of hybrid vehicles diminish by about $13 \%$, and $11 \%$ for conventional and natural gas vehicles. ${ }^{12}$

In scenario 3, subsidies, as they are currently granted in several European countries, reduce the investment cost of PHEVs, electric, and hydrogen vehicles, and lead to purchase prices of $€ 27,700$ for PHEVs, $€ 31,800$ for electric vehicles, and $€ 28,800$ for hydrogen cars. Such a governmental promotion strategy increases the choice probability for hydrogen vehicles by approximately 36\%, electric cars by about 35\%, and PHEVs by almost $13 \%$, compared with the base case scenario, while all other fuel types lose market shares (conventional and natural gas vehicles roughly 5\%, and hybrid and biofuel vehicles about 6\%).

The effect of identical purchase prices of all vehicle alternatives is analyzed in scenario 4 . It increases the choice probability significantly: for electric cars by $117 \%$, hydrogen vehicles by almost $81 \%$, PHEVs by approximately $33 \%$, and hybrid cars by more than $2 \%$, compared to the base case, while the market shares of the remaining vehicle alternatives decrease (for conventional and biofuel cars by about $23 \%$ and $21 \%$, respectively, and natural gas vehicles by $10 \%)$.

The availability of battery leasing contracts for electric vehicles considered in scenario 5 increases the choice probability by about $26 \%$, correspondingly drawing market shares from all other vehicle alternatives from between $0.5 \%$ to $0.8 \%$. Thus, battery leasing contracts appear to be unable to considerably push the demand for electric vehicles. However, this finding should be treated with some caution, as we simply convert the monthly cost of the battery leasing contract into additional fuel cost, whereas it is reasonable that car buyers will evaluate a fixed monthly battery leasing payment differently from an increase in fuel cost. Furthermore, we do not consider the benefit of battery leasing contracts as a risk reduction

\footnotetext{
${ }^{12}$ Note that the unequal substitution between the different vehicle types is a result of applying an MXL model, which accounts for correlations between some of the vehicle alternatives.
} 
measure, given the unfamiliar technology and unknown battery lifetime, which could bias our simulation results and thus lead to an underestimate of their influence on the choice of electric vehicles.

The improvement of the driving range for electric vehicles to $750 \mathrm{~km}$, tackled in scenario 6, and thus resulting in a driving range comparable to most other AFVs, leads to a substantial increase in demand for electric vehicles of more than $143 \%$, while the market shares of all other fuel types diminish by approximately $3 \%$ to $5 \%$, relative to the base case, drawing most heavily from the two other electrified vehicle alternatives.

In scenario 7, the service station density is assumed to be the same for all vehicles, so that in this respect, all AFVs are competitive with conventional cars. Such a massive investment in the refueling infrastructure decreases the choice probabilities of conventional and hybrid cars by about $15-16 \%$, while the demand for all other vehicle alternatives increases by between $6 \%$ (for natural gas cars) and about 30\% (for hydrogen vehicles). Comparing our results with those of Daziano and Achtnicht (2012), we find that their results are much more optimistic with regard to electric and hydrogen vehicles. In their high refueling station density scenario, which is comparable to our scenario 7 , they find a market share of almost $12 \%$ for electric vehicles and $22 \%$ for hydrogen vehicles, while the demand for these two vehicle alternatives in our simulation only amounts to some $3 \%$ and $8 \%$, respectively. One reason for this discrepancy could be that they do not consider the longer recharging time and the limited driving range of electric vehicles, which both put electric vehicles at a disadvantage. This is the case in reality and, therefore, also considered in our model. Furthermore, our estimation results indicate that the refueling station density is not as important as suggested by Daziano and Achtnicht (2012) and, thus, its impact on vehicle choice is reduced in our scenario analysis. Consequently, even when we follow their approach and separately and subsequently vary the density of the recharging/refueling network for electric or hydrogen vehicles, leaving it unchanged for all other fuel types, in the high filling station density scenario, electric vehicles still only gain a market share of about 3\%, and hydrogen vehicles capture approximately $9 \%$ of the market. This is only slightly more than in our original findings and still not comparable to the results of Daziano and Achtnicht (2012).

The reduction of the battery recharging time to 5 minutes (scenario 8), making the duration and thus the comfort of the refueling process similar to all other vehicle options, leads to an increase in the market shares of the two plug-in vehicle types (i.e. to more than $46 \%$ for 
electric vehicles and $8 \%$ for PHEVs), while all other vehicle options are chosen less frequently, compared to the base case scenario, by between about 2-3\%.

In scenario 9, governmental monetary and non-monetary incentives and the provision of a spatially comprehensive refueling and fast-charging infrastructure, leads to a substantial loss in the demand for conventional vehicles of 30\%, while all other AFVs reach almost equal market shares (13-18\%), whereas PHEVs even become the second-most popular vehicle alternative. The only exception are electric vehicles, with a market share of merely about $5 \%$, which compared to the base case nevertheless show more than a doubling in the choice probability.

In summary, the scenario simulations show that conventional vehicles can be expected to further dominate the vehicle market, as they feature the highest choice probability in all scenarios. Natural gas and hybrid vehicles are the most likely chosen AFVs, although this difference in preference for the various AFVs vanishes, the more pronounced the marketbased policy intervention is (e.g. scenario 9). In all scenarios except scenario 9, (partially) electrically propelled vehicles do not gain substantial market shares (PHEVs mostly take fifth place in choice probability) and electric vehicles consistently feature the lowest demand. Furthermore, it can be seen that hydrogen vehicles only capture a small market share and are the second most disliked option after electric vehicles in almost all scenarios (except for scenarios 4 and 9). Interestingly, car buyers choose biofueled cars even when the density of gasoline stations offering biofuel is low.

When comparing the different policy measures in the eight scenarios with each other and with the base case, we can analyze how the different actions impact the choice probabilities for the different fuel/propulsion types. For instance, the market share of natural gas and biofuel vehicles is largest in scenario 7, for PHEVs and hydrogen in scenario 9, and for electric vehicles in scenarios 6 and 9. The influence on hybrid vehicles is, except for a strong negative impact in scenario 9, quite small across all other scenarios, with the highest choice probability found in scenario 2. Conventional fuels lose market shares in all scenarios, with this influence being lowest in scenario 5. Overall, the strongest impact on the vehicle market is found in scenarios 4, 7, and 9. Furthermore, we find evidence that the choice probabilities of some AFVs (PHEVs, biofuel, and hydrogen vehicles) could be increased quite easily and in a relatively budget-friendly way (scenario 2), or at least with a relatively manageable governmental purchase grant (scenario 3), while such financial and non-monetary 
governmental incentives are unable to effectively accelerate electric vehicle adoption unless the subsidies are substantial (as in scenario 4). Opposed to this, battery leasing contracts have almost no influence on all vehicle alternatives, since even electric vehicles only slightly gain market share (scenario 5). A very interesting finding is that an increase in the driving range to $750 \mathrm{~km}$ for electric vehicles (scenario 6) has the same effect as monetary and non-monetary incentives and a fast-charging infrastructure taken together (scenario 9). A fully developed refueling infrastructure, in contrast, mainly increases the demand for those vehicle alternatives that run on liquid or gaseous fuels and currently suffer from a sparse filling station density (scenario 7), such as hydrogen and biofuel vehicles. Furthermore, the results of scenario 8 show that just accelerating the recharging process alone does not markedly increase the choice probability of plug-in vehicles. Finally, and surprisingly, a massive market-based intervention by the government (scenario 9), which we assumed to be beneficial at least for all non-fossil fueled AFVs, shows almost no effect on the market share of biofuel cars. These findings from our study could be relevant both for public and private decisión-makers aiming to promote consumer adoption of alternative vehicle technologies.

\section{Conclusions}

In this paper we have studied the preferences and resulting implications for alternative fuel vehicles in Germany. Expanding earlier studies, we have additionally taken recharging time, driving range, and governmental incentives as crucial vehicle features into account to measure their respective impact on vehicle choice decisions. Furthermore, we considered PHEVs and their unique characteristics as a vehicle alternative. By using discrete choice data from a nation-wide survey in Germany and applying both a standard MNL model and an MXL model specification, we find that, except refueling time, all vehicle attributes considered are highly statistically significant. The attributes impact vehicle choice positively, as in the case of driving range, fuel availability, and governmental monetary and non-monetary incentives, or negatively, as in the case of purchase price, fuel cost, $\mathrm{CO}_{2}$ emissions, and recharging time. Furthermore, we find that German car buyers are currently very reluctant toward AFVs, especially electric and hydrogen vehicles, which could be a great barrier in terms of their fast and successful diffusion and to achieving the very ambitious goal of the German government to get 1 million electric cars on the road by 2020. However, our results also show that PHEVs are far less likely to be rejected than fully electric vehicles and that not all consumers have 
equally pronounced reservations against AFVs. In other words, especially younger, highly educated, and environmentally conscious consumers, and to some extent also urban drivers of small cars with access to a parking lot equipped with a socket, are more prone to buy new vehicle technologies in general and plug-in cars in particular. Hence, marketing strategies could be tailored such that they target specifically these consumer groups for effectively increasing the adoption rates (or sales figures) of certain AFVs. On the contrary, and in light of the ongoing demographic change resulting in an ageing population, our results could also lead to the opposite conclusion that the most relevant target group for policy-makers and car manufacturers should be middle aged and elderly people, as they still have strong reservations against electric vehicles, and thus could threaten the prospects for individual electric mobility of private vehicle users and, consequently, the ambitious goal of the German government to become a lead market. Therefore, information campaigns or the possibility to test electric vehicles in the field could be especially customized for these consumer groups to reduce their unfamiliarity with, and reservations against, electric mobility.

Additionally, we find that German car buyers are willing to pay considerable amounts for an improvement of the most important vehicle features. However, notable differences in the WTP can be observed, depending on the consumer group or the respective vehicle alternative. For instance, the marginal WTP for the mitigation of $\mathrm{CO}_{2}$ emissions is more than twice as large for highly environmentally aware (potential) adopters, compared with adopters with low environmental consciousness. A similar doubling can be observed for the driving range of electric versus other vehicles, and for a reduction in battery recharging time between PHEVs and full electric cars. This finding indicates that a fast-charging option is not equally important for all plug-in vehicles, and thus could be relevant for the recharging infrastructure investment strategy. Furthermore, households with low stated purchase prices $(<€ 20,000)$ are only willing to pay about half the amount that households without this budget constraint are willing to expend for the improvement of vehicle features.

The scenario analysis revealed that conventional vehicles remain dominant in terms of market share, and that hybrid and natural gas vehicles are the AFVs most likely to be chosen. As these propulsion technologies are currently the most renowned and available AFVs, and as they also have the farthest-developed refueling infrastructure and do not suffer from short driving ranges or high purchase prices surcharges, this finding is not too surprising. Interestingly, however, our results show that choice probabilities of some AFVs, such as 
PHEVs and biofuel vehicles, could be increased in a relatively cost-efficient way by granting vehicle tax exemptions, or by allowing the usage of bus lanes and presenting possibilities for free parking. Thus, to promote AFVs, the German government should think about the introduction of these incentives and not limit these measures to electric vehicles. Contrary to that finding, fully electric and hydrogen vehicles only gain in demand if multiple policy measures are implemented or at least the subsidization of the vehicle purchase is substantial. Thus, financial incentives as they are used in some European countries today, and also lobbied for by German car manufacturers, are found to be insufficient to significantly increase adoption rates. Furthermore, our results suggest that an expansion of the refueling/recharging infrastructure density or the acceleration of the recharging process alone is not sufficient for increasing the diffusion of electric vehicles, but that these two measures should rather be implemented jointly. Finally, and also very interestingly, our findings indicate that an increase in the driving range of fully electric vehicles to $750 \mathrm{~km}$ affects the adopters' choice probability in the same way as would a market based multiple policy intervention strategy, comprising a purchase price subsidy, a tax waiver, bus lane usage, free parking, and a widespread fast-charging infrastructure. Future research will thus have to identify whether the government is advised to better provide public funds for battery $\mathrm{R} \& \mathrm{D}$ or for monetary incentives and infrastructure, like fuel stations for all AFVs or fast-charging options for electric vehicles, as both make the adoption more attractive for potential electric vehicle users.

In order to reach the very ambitious electric mobility goal of the German government, further research is also needed with regard to the types of potential adopters that are particularly influenced by the vehicle attributes currently disfavouring electric vehicles, e.g. short driving ranges and lengthy recharging processes, and their respective WTP for their improvement, to individually customize incentive and subsidization schemes or marketing and sales programs. A further option for the government could be to increasingly focus on and promote PHEVs (e.g. with subsidies and non-monetary incentives), as they are not burdened by limited cruising ranges and thus could serve as a means to make car drivers familiar with electric mobility, without putting them at risk of being stranded due to an empty battery. 


\section{References}

ACEA - European Automobile Manufacturers' Association, 2012. Overview of purchase and tax incentives for electric vehicles in the EU (as of March 29, 2012). [Online] URL: http://www.acea.be/images/uploads/files/Electric_vehicles_overview.pdf [accessed October 5, 2012].

Achtnicht, M., 2012. German car buyers' willingness to pay to reduce $\mathrm{CO}_{2}$ emissions. Climatic Change 113(3-4), 679-697.

Achtnicht, M., Bühler, G., Hermeling, C., 2012. The impact of fuel availability on demand for alternative-fuel vehicles. Transportation Research Part D 17(3), 262-269.

ADAC - Allgemeiner Deutscher Automobil-Club e.V., 2012a. Monatliche Durchschnittspreise Kraftstoffe seit 2000. [Online] URL: http://www.adac.de/infotestrat/tanken-kraftstoffe-und-antrieb/kraftstoffpreise/kraftstoffdurchschnittspreise/default.aspx? ComponentId=51587\&SourcePageId=54981 [accessed October 25, 2012].

ADAC - Allgemeiner Deutscher Automobil-Club e.V., 2012b. Elektroautos: Marktübersicht/Kenndaten. [Online] URL: http://www.adac.de/_mmm/ pdf/27373_46583.pdf [accessed October 25, 2012].

ADAC - Allgemeiner Deutscher Automobil-Club e.V., 2012c. Welche Motorversion ist die günstigste? ADAC Kostenvergleich: Erd- und Autogas gegen Benziner und Diesel. [Online] URL: http://www.adac.de/_mmm/pdf/g-b-d-vgl_47097.pdf [accessed October 25, 2012].

ADAC - Allgemeiner Deutscher Automobil-Club e.V., 2012d. Weg vom Öl - Alternative Antriebe. [Online] URL: http://www.adac.de/infotestrat/tanken-kraftstoffe-undantrieb/alternative-kraftstoffe/default.aspx [accessed October 25, 2012].

Ahn, J., Jeong, G. Kim, Y., 2008. A forecast of household ownership and use of alternative fuel vehicles: A multiple discrete-continuous choice approach. Energy Economics 30(5), 2091-2104.

Axsen, J., Mountain, D.C., Jaccard, M., 2009. Combining stated and revealed choice research to simulate the neighbor effect: The case of hybrid-electric vehicles. Resource and Energy Economics 31(3), 221-238.

Batley, R.P.; Toner, J.P., Knight, M.J., 2004. A mixed logit model of U.K. household demand for alternative-fuel vehicles. International Journal of Transport Economics 31(1), 55-77. 
Beggs, S., Cardell, S., Hausman, J., 1981. Assessing the potential demand for electric cars. Journal of Econometrics 17(1), 1-19.

BImSchG - Bundes-Immissionsschutzgesetz (Federal Immission Control Act), 2011. Act on the prevention of harmful effects on the environment caused by air pollution, noise, vibration and similar phenomena in the version promulgated on 26 September 2002 (BGBl. I p. 3830), as last amended by Article 8 of the Act of 8 November 2011 (BGBl. I p. 2178), Federal Office Journal, Bonn.

BMF - Federal Ministry of Finance, 2011. Übersicht zur Kraftfahrzeugsteuer für Personenkraftwagen mit Erstzulassung ab 1.7.2009. Berlin, December. [Online] URL: http://www.bundesfinanzministerium.de/Content/DE/Standardartikel/Themen/Steuern/ Steuerarten/Kraftfahrzeugsteuer/Merkblaetter_und_Uebersichten/kfz-steuer-fuerpersonenkraftwagen.html [accessed December 18, 2012].

BMVBS/BMWi/BMBF - Federal Ministry of Transport, Building, Urban Development / Federal Ministry of Economics and Technology / Federal Ministry of Education and Research, 2006. National hydrogen and fuel cell technology innovation programme (NIP). Berlin, May.

BMWi - Federal Ministry of Economics and Technology, 2012. Entwicklung von Energiepreisen und Preisindizes (as of April 13, 2012). [Online] URL: http://www.bmwi.de/DE/Themen/Energie/Energiedaten/energiepreise-energiekosten.html [accessed October 25, 2012].

Brownstone, D., Bunch, D.S., Train, K., 2000. Joint mixed logit models of stated and revealed preferences for alternative-fuel vehicles. Transportation Research Part B 34(5), 315-338.

Brownstone, D., Train, K., 1999. Forecasting new product penetration with flexible substitution patterns. Journal of Econometrics 89(1-2), 109-129.

Bunch, D.S., Bradley, M., Golob, T.F., Kitamura, R., Occhiuzzo, G.P., 1993. Demand for clean-fuel vehicles in California: A discrete-choice stated preference pilot project. Transportation Research Part A 27(3), 237-253.

Bundesregierung, 2009. German Federal Government’s national electromobility development plan. Berlin, August.

Bundesregierung, 2011. Regierungsprogramm Elektromobilität. Berlin, May.

Calfee, J.E., 1985. Estimating the demand for electric automobiles using fully disaggregated probabilistic choice analysis. Transportation Research Part B 19(4), 287-301. 
Caulfield, B., Farrell, S., McMahon, B., 2010. Examining individuals preferences for hybrid electric and alternatively fuelled vehicles. Transport Policy 17(6), 381-387.

CEP - Clean Energy Partnership, 2012. What does hydrogen cost? [Online] URL: http://www.cleanenergypartnership.de/en/faq/\#c245 [accessed October 25, 2012].

Dagsvik, J.K., Wennemo, T., Wetterwald, D.G., Aaberge, R., 2002. Potential demand for alternative fuel vehicles. Transportation Research Part B 36(4), 361-384.

DAT - Deutsche Automobil Treuhand GmbH, 2012. DAT-Report 2012. [Online] URL: http://www.dat.de/uploads/media/DAT-Report_2012_Kfz-Betrieb.pdf [accessed December 15, 2012].

Daziano, R.A., Bolduc, D., 2011. Incorporating pro-environmental preferences towards green automobile technologies through a Bayesian hybrid choice model. Transportmetrica iFirst, 1-33.

Daziano, R.A., Achtnicht, M., 2012. Forecasting adoption of ultra-low-emission vehicles using the GHK simulator and Bayes estimates of a multinomial probit model. ZEW Discussion Paper No. 12-017, Center for European Economic Research, Mannheim.

Dena - German Energy Agency, 2010. Repräsentativbefragung - Umfrage zum Thema "Autokauf“ (29.03.2010). [Online] URL: http://www.ichundmeinauto.info/ fileadmin/user_upload/Presse/100308_ich-und-mein-auto_Repraesentativbefragung Autokauf_Thema_Kaufkriterien.pdf [accessed December 20, 2011].

EC, 2009a. Directive 2009/28/EC of the European Parliament and of the Council on the promotion of the use of energy from renewable sources. April.

EC, 2009b. Regulation (EC) No 443/2009 of the European Parliament and of the Council setting emission performance standards for new passenger cars as part of the Community's integrated approach to reduce $\mathrm{CO}_{2}$ emissions from light-duty vehicles. April.

EC, 2011a. Energy, transport and environment indicators. Publications Office of the European Union, European Commission/Eurostat, Luxembourg.

EC, 2011b. White Paper - Roadmap to a single European transport area - Towards a competitive and resource efficient transport system. COM(2011) 144 final, European Commission, Brussels, March.

Ewing, G., Sarigöllü, E., 2000. Assessing consumer preferences for clean-fuel vehicles: A discrete choice experiment. Journal of Public Policy and Marketing 19(1), 106-118. 
Golob, T.F., Kitamura, R., Bradley, M., Bunch, D.S., 1993. Predicting the market penetration of electric and clean-fuel vehicles. The Science of the Total Environment 134(1-3), 371381.

Greene, D.L., 2010. How consumers value fuel economy: A literature review. Technical report for the United States Environmental Protection Agency, EPA-420-R-10-008, March.

Grüning, M., Witte, M., Marcellino, D., Selig, J., van Essen, H., 2011. Impact of electric vehicles - Deliverable 1: An overview of electric vehicles on the market and in development. CE Delft, Delft, April.

Hidrue, M.K., Parsons, G.R., Kempton, W., Gardner, M., 2011. Willingness to pay for electric vehicles and their attributes. Resource and Energy Economics 33(3), 686-705.

Horne, M., Jaccard, M., Tiedemann, K., 2005. Improving behavioral realism in hybrid energy-economy models using discrete choice studies of personal transportation decisions. Energy Economics 27(1), 59-77.

Ito, N., Takeuchi, K., Managi, S., 2013. Willingness-to-pay for infrastructure investments for alternative fuel vehicles. Transportation Research Part D 18(1), 1-8.

Lebeau, K., Van Mierlo, J., Lebeau, P., Mairesse, O., Macharis, C., 2012. The market potential for plug-in hybrid and battery electric vehicles in Flanders: A choice-based conjoint analysis. Transportation Research Part D 17(8), 592-597.

Louviere, J.J., Hensher, D.A., Swait, J.D., 2003. Stated Choice Methods - Analysis and Applications. Cambridge University Press, Cambridge.

Mabit, S.L., Fosgerau, M., 2011. Demand for alternative-fuel vehicles when registration taxes are high. Transportation Research Part D 16(3), 225-231.

Malins, C., 2012. A model-based quantitative assessment of the carbon benefits of introducing iLUC factors in the European Renewable Energy Directive. GCB Bioenergy (doi: 10.1111/j.1757-1707.2012.01207.x).

Mau, P., Eyzaguirre, J., Jaccard, M., Collins-Dodd, C., Tiedemann, K., 2008. The 'neighbor effect': Simulating dynamics in consumer preferences for new vehicle technologies. Ecological Economics 68(1-2), 504-516.

McKinsey \& Company, 2010. A portfolio of power-trains for Europe: A fact-based analysis The role of battery electric vehicles, plug-in hybrids and fuel cell electric vehicles. Study on behalf of a coalition of European companies and organizations, Düsseldorf. 
Musti, S., Kockelman, K.M., 2011. Evolution of the household vehicle fleet: Anticipating fleet composition, PHEV adoption and GHG emissions in Austin, Texas. Transportation Research Part A 45(8), 707-720.

Nunnally, J.C., Bernstein, I.H., 1994. Psychometric Theory. $3^{\text {rd }}$ edition, McGraw-Hill, New York.

Potoglou, D., Kanaroglou, P.S., 2007. Household demand and willingness to pay for clean vehicles. Transportation Research Part D 12(4), 264-274.

Preisendörfer, P., 1999. Umwelteinstellungen und Umweltverhalten in Deutschland Empirische Befunde und Analysen auf der Grundlage der Bevölkerungsumfragen „Umweltbewußtsein in Deutschland 1991-1998“. Leske und Budrich, Opladen.

Train, K.E., 2003. Discrete Choice Methods with Simulation. Cambridge University Press, Cambridge.

Wietschel, M., Bünger, U., Weindorf, W., 2010. Vergleich von Strom und Wasserstoff als CO2-freie Endenergieträger. Final report of a study on behalf of RWE AG, Karlsruhe, May.

Ziegler, A., 2012. Individual characteristics and stated preferences for alternative energy sources and propulsion technologies in vehicles: A discrete choice analysis for Germany. Transportation Research Part A 46(8), 1372-1385.

Zilberman, D., Hochman, G., Rajagopal, D., Sexton, S., Timilsina, G., 2012. The impact of biofuels on commodity food prices: Assessment of findings. American Journal of Agricultural Economics, doi: 10.1093/ajae/aas037. 